\title{
The salience of nonlinearities in the boreal winter response to ENSO: Arctic stratosphere and Europe
}

\author{
Israel Weinberger ${ }^{1}$ (1) Chaim I. Garfinkel ${ }^{1} \cdot \operatorname{lan}$ P. White ${ }^{1} \cdot$ Luke D. Oman $^{2}$
}

Received: 8 October 2018 / Accepted: 6 May 2019 / Published online: 24 May 2019

(c) The Author(s) 2019

\begin{abstract}
The Arctic stratospheric response to El Niño (EN) and La Niña (LN) is evaluated in a 41 member ensemble of the period 1980 to 2009 in the Goddard Earth Observing System Chemistry-Climate Model. We consider whether the responses to EN and LN are equal in magnitude and opposite in sign, whether the responses to moderate and extreme events are proportionate, and if the response depends on whether sea surface temperature anomalies (SSTs) peak in the Eastern Pacific (EP) or Central Pacific (CP). There is no indication of any nonlinearities between EN and LN, though in 15\% of the ensemble members the stratospheric sudden warming (SSW) frequencies for EN and LN are similar, suggesting that a similar SSW frequency for EN and LN, as has occurred over the past $\sim 60$ years, can occur by chance. The response to extreme EN events is not proportionate to the amplitude of the underlying SST anomalies in spring. EP EN events preferentially increase zonal wavenumber 1 and decrease zonal wavenumber 2 as compared to CP EN events, however the zonal-mean Arctic stratospheric and subpolar surface response is generally little different between EP EN and CP EN once one accounts for the relative weakness of CP events. These differences between EP and CP events and between moderate and extreme EN events only emerge if at least 25 events are composited, however, due to the small signal-to-noise ratio, and hence these differences may be of little practical benefit.
\end{abstract}

\section{Introduction}

El Niño Southern Oscillation (ENSO), i.e. the warm (El Niño hereafter EN) and cold (La Niña hereafter LN) phases of the equatorial Pacific coupled atmosphere-ocean phenomenon, impacts the global atmospheric circulation in both the troposphere (Horel and Wallace 1981; Ropelewski and Halpert 1987; Halpert and Ropelewski 1992; Trenberth et al. 1998) and stratosphere (van Loon and Labitzke 1987; Hamilton 1993; Domeisen et al. 2019). EN leads to an accelerated Brewer-Dobson circulation and a warmer polar stratosphere on average by several degrees Kelvin (Sassi et al. 2004; Garcia-Herrera et al. 2006; Garfinkel and Hartmann 2007; Camp and Tung 2007; Free and Seidel 2009).

The Arctic stratospheric response during EN events is driven specifically by the deepened Aleutian low (e.g.

Israel Weinberger

israel.weinberger@mail.huji.ac.il

1 The Fredy and Nadine Herrmann Institute of Earth Sciences, Hebrew University of Jerusalem, Jerusalem, Israel

2 NASA Goddard Space Flight Center, Greenbelt, MD, USA
Barnston and Livezey 1987), which constructively interferes with the climatological stationary wave pattern and leads to a strengthened wave flux into the stratosphere (i.e. linear interference; Garfinkel and Hartmann 2008; Garfinkel et al. 2010; Smith et al. 2010; Smith and Kushner 2012). Episodes of prolonged upward wave flux can lead to sudden stratospheric warming (SSW) events (Polvani and Waugh 2004; Sjoberg and Birner 2012), and on average, modulate surface climate (Cagnazzo et al. 2009; Ineson and Scaife 2009; Bell et al. 2009) and thus increase weather predictability (Sigmond et al. 2013) in the Euro-Atlantic region for weeks.

It is not clear to what extent the Arctic stratospheric response to $\mathrm{LN}$ is opposite to that of $\mathrm{EN}$. While in the seasonal mean strong LN events appear to lead to a stronger and colder than normal Arctic polar vortex (Garfinkel and Hartmann 2007; Iza et al. 2016), there is no reduction in the frequency of SSW events during LN winters (Butler and Polvani 2011; Polvani et al. 2017; Domeisen et al. 2019). Two explanations have been offered as to why LN should not lead to reduced SSW frequency: first, the North Pacific ridge associated with LN does not reach the subpolar Northwest Pacific where it could most efficiently destructively interfere with the climatological stationary waves 
(Garfinkel et al. 2012), and second, the North Pacific ridge and enhanced blocking associated with LN extends over the Northeast Pacific where it can lead to enhanced wavenumber 2 driving of the vortex (Barriopedro and Calvo 2014). However, models do not succeed in capturing such a relationship between LN and SSW (Taguchi and Hartmann 2006; Bell et al. 2009; Garfinkel et al. 2012; Li and Lau 2013; Domeisen et al. 2015; Polvani et al. 2017; Song and Son 2018), and hence it is unclear whether the lack of a reduced SSW frequency in LN in the reanalysis record might simply be related to random variability in a relatively short record, or alternately whether models have biased teleconnections during LN (Butler and Polvani 2011; Garfinkel et al. 2012; L'Heureux et al. 2017). Furthermore, the observed LN-SSW relationship has also been shown to be sensitive to how LN events and SSW events are classified (Polvani et al. 2017; Song and Son 2018).

No two EN events have identical sea surface temperature (SST) anomalies, and it is unclear whether differences in the SST pattern are crucial for the stratospheric response. EN events differ both in their magnitude, with some eventse.g. 1997/1998, 1982/1983 and 2015/2016 - stronger than others, and in the location within the tropical Pacific where maximum SST anomalies are observed. Specifically, for Central Pacific (CP) EN events, also called a dateline EN event (Larkin and Harrison 2005), SST anomalies peak in the central equatorial Pacific, while for East Pacific (EP) EN events SST anomalies peak in the eastern equatorial Pacific.

While it is reasonable to expect that stronger events lead to stronger tropical precipitation anomalies, the increase is not linear (Frauen et al. 2014; Rao and Ren 2016a). These nonlinearities could lead to a nonlinear stratospheric response, but detecting such a nonlinearity in observations is difficult. Rao and Ren (2016a) composite moderate EN and strong EN events separately and conclude that moderate events modulate the northern winter stratosphere more robustly. However, the salience of such nonlinearities appears to depend on the methodology adopted as it is difficult to detect such a nonlinearity given the large amount of internal variability in Figure 11 of Rao and Ren (2016a). Modeling studies disagree as to whether nonlinearities are present: Rao and Ren (2016b) find evidence for nonlinearity, but Richter et al. (2015) find that the modeled response to the $1997 / 1998$ and $1982 / 1983 \mathrm{EN}$ events is more than double the response to moderate events, implying that the response to EN is linear. The recent study by Zhou et al. (2018) argues that the response in spring is linear, and any nonlinearities are confined to earlier in winter. The European sector response may be similarly nonlinear (Toniazzo and Scaife 2006; Bell et al. 2009).

Finally, both EP EN and CP EN events lead to a deepened Aleutian low (Yu and Kim 2011) though the deepening is stronger for eastern Pacific events especially in early winter
(Yu and Kim 2011; Sung et al. 2014). CP EN events lead to a southward and westward displacement of the anomalously low sea level pressure relative to EP EN events (Yu and Kim 2011; Garfinkel et al. 2013, 2018b), and this southward displacement of the Aleutian low, as well as the relative weakness of the amplification, could lead to weaker impacts in the Arctic stratosphere during CP EN events. However, it is not yet possible to discriminate between the teleconnections of CP EN and EP EN events in a statistically robust manner that is not sensitive to methodological choices in observations (Garfinkel et al. 2013; Iza and Calvo 2015). Modeling studies have also not yet reached a consensus on whether robust differences exist between the stratospheric response to CP EN and EP EN events. Some studies have concluded that only EP EN events lead to a weakening of the vortex (Xie et al. 2012; Calvo et al. 2017), some find little robust difference in the response between CP EN and EP EN events (Hegyi et al. 2014; Hurwitz et al. 2014), while others argue that both lead to weakening of the polar vortex, but with the vortex weakening during EP EN more pronounced in early winter (Garfinkel et al. 2013) or in the absence of SSWs (Iza and Calvo 2015). Even if the modulation of the vortex is somewhat weaker during CP EN events, the impacts in the Euro-Atlantic sector found in some studies is stronger (e.g. Graf and Zanchettin 2012; Garfinkel et al. 2013), suggesting that EN can modulate the vortex via a purely tropospheric route (Butler et al. 2014; Rodríguez-Fonseca et al. 2016; Jiménez-Esteve and Domeisen 2018).

Given the importance of the stratosphere for European sector winter variability (Charlton et al. 2003; Baldwin et al. 2003), and given the uncertainties in the European response to ENSO (Toniazzo and Scaife 2006; Brönnimann 2007), here we seek to clarify some of these lingering uncertainties in the linearity of the stratospheric response to ENSO. We address these lingering uncertainties by first identifying the nonlinear responses to ENSO in the wavedriving of the Arctic polar vortex, in the Arctic stratosphere, and in the subsequent downward impact on the troposphere. For each of these regions, We address three target questions:

1. Are the responses to EN and $\mathrm{LN}$ equal in magnitude and opposite in sign?

2. Is the magnitude of the response to extreme EN events proportionately stronger than that of moderate EN events?

3. Are the responses to different EN flavors (i.e, EP EN and CP EN events) similar?

In the rest of this paper we refer to the atmospheric response as 'linear' when the responses to EN and LN are equal in magnitude and opposite in sign, the response to moderate vs extreme events is proportional and there is no significant difference between the responses to EP EN and CP EN events. 
Whenever nonlinearities are found, we ask the additional question: how many samples (events) does one need in order to establish the robustness of these nonlinearities?

After introducing the data and methods in Sects. 2 and 3, we demonstrate that the modulation of the wave-driving of the vortex by ENSO is nearly linear, though there are differences in the wavenumber composition of the modulated wave-driving between CP EN and EP EN events (Sect. 4) that in turn affects the morphology of stratospheric sudden warmings for each El Niño flavor. The Arctic stratospheric response to ENSO is effectively linear in winter, though in spring extreme EN events do not lead to a proportionately stronger response (Sect. 5). The linearities and nonlinearities of the stratospheric response are mostly mirrored in the surface response (Sect. 6). However detecting these nonlinearities is very difficult: the anomalies forced by ENSO are small as compared to the internal variability in the extratropical atmosphere, and specifically, individual ensemble members may display apparent nonlinearities in SSW frequency that are in many ways similar to those observed even if none exist in the ensemble mean response (Sect. 7).

\section{Data}

The foundation of this study is an ensemble of integrations conducted using the Goddard Earth Observing System Chemistry-Climate Model (GEOSCCM Rienecker et al. 2008; Oman and Douglass 2014) described in Garfinkel et al. (2018a, b). This model couples the GEOS-5 (Rienecker et al. 2008; Molod et al. 2012) atmospheric general circulation model to the comprehensive stratospheric chemistry module StratChem (Pawson et al. 2008). The model has 72 levels, with a model top at $0.01 \mathrm{hPa}$, and the horizontal resolution of all integrations discussed here is $2^{\circ}$ latitude $\times$ $2.5^{\circ}$ longitude. The model spontaneously generates a QuasiBiennial Oscillation (QBO) (Molod et al. 2012), though the QBO phase is not synchronized with the observed QBO or among the experiments. One of the integrations of Garfinkel et al. (2018a) ends in December 2008, and we do not include this integration here. 41 ensemble members covering the period 1980 to 2009 are analyzed, and all are free-running and have observed sea surface temperature (SST) variations imposed globally. Full details of the model ensemble are included in Garfinkel et al. (2018a). These same experiments were analyzed in Garfinkel et al. (2018a, b) with a focus on the surface impacts of ENSO over North Pacific and North America and on the tropical stratosphere; here we focus on the Arctic stratospheric response and the subpolar surface response.

An imposed-SST ensemble like the one analyzed here allows a natural comparison to the observed response to ENSO, and model output is compared to meteorological fields from MERRA (Modern-era retrospective analysis for research and applications; Rienecker et al. 2011) and ERAInterim (ERAI) reanalysis (Dee et al. 2011).

\section{Methods}

The ENSO phase for each winter season is defined by SST anomalies in the Niño3.4 region $(5 \mathrm{~S}-5 \mathrm{~N}, 170 \mathrm{~W}-120 \mathrm{~W})$ in version 5 of the ERSST dataset (Huang et al. 2017) with a 1980-2009 base period. We first apply a 1-2-1 running mean smoothing on the Niño3.4 index for each set of three months (e.g. weights of $1 / 4$ are applied to months $n+1$ and $n-1$ and a weight of $1 / 2$ is applied to month $n$ ). We then define a season as EN or LN based on the NDJF seasonal mean Niño3.4 anomalies. Other studies have adopted alternate definitions, and in the appendix we discuss sensitivity to the detailed manner in which events are chosen. In the interest of simplicity the main text adopts the NDJF seasonal mean definition.

EN events are identified when SST anomalies in the Niño3.4 region, are larger than $0.5 \mathrm{~K}$. EN events are further categorized as Eastern Pacific El Niño (EP EN) and Central Pacific El Niño (CP EN). EP EN events are identified when the Niño3 region (5S-5N, 210E-270E) SST anomaly is positive and $0.1 \mathrm{~K}$ larger than the Niño4 region $(5 \mathrm{~S}-5 \mathrm{~N}$, 160E-210E) anomaly (similar to Hurwitz et al. 2014), after applying a 1-2-1 running mean smoothing to the Niño3 and Niño4 indices. As we would like to discern whether differences in the response to EP EN and CP EN are due to differences in the position of tropical convection and not due to differences in event amplitude, we further divide the EP EN events into "extreme" events (i.e. 82/83 and 97/98) and "moderate" events (1986/1987, 1991/1992, See Table 1). CP EN events are identified when the Niño4 SST anomaly is positive and $0.1 \mathrm{~K}$ larger than the Niño3 SST anomaly, after applying a 1-2-1 running mean smoothing to the Niño3 and Niño4 indices. Composited anomalies during EP and CP events depend on the specific definition adopted, however the two years identified herein as CP EN (1994/1995 and 2004/2005) are so classified for nearly all CP definitions (e.g Garfinkel et al. 2013; Johnson and Kosaka 2016). The 1991/1992 event can be classified as a Modoki event (Ashok et al. 2007; Garfinkel et al. 2013), however this classification is mainly due to the cold SST anomalies that were present over the far Western Pacific as SSTs in the East Pacific Niño3 region were indeed warmer than those in the Central Pacific Niño4 region. Note that SST anomalies in the Niño3.4 region are still 30\% stronger for the moderate EP EN events than the CP EN events. All remaining EN years, in which the Niño3 and Niño4 anomalies are within $0.1 \mathrm{~K}$, are categorized as "other EN events".

LN events are identified when SST anomalies in the Niño3.4 region are below $-0.5 \mathrm{~K}$. In our presentation of the 
Table 1 Events included for each ENSO composite

\begin{tabular}{ll}
\hline ENSO composites & \\
\hline Composite & Years \\
\hline Moderate EP EN & $1986 / 1987,1991 / 1992$ \\
Extreme EP EN & $1982 / 1983,1997 / 1998$ \\
CP EN & $1994 / 1995,2004 / 2005$ \\
Other EN & $1987 / 1988,2002 / 2003,2006 / 2007$ \\
EP LN & $1984 / 1985,1995 / 1996,1999 / 2000,2005 / 2006,2007 / 2008$ \\
CP LN & $1983 / 1984,1988 / 1989,1998 / 1999,2000 / 2001,2008 / 2009$ \\
\hline
\end{tabular}

response to $\mathrm{LN}$, we do not separately consider CP LN and EP LN events, because the response to CP LN and EP LN events was found to not be robustly different in our ensemble for any metric despite the availability of hundreds of model-seasons (not shown). We therefore form a single $\mathrm{LN}$ composite, and we also include in this LN composite years that cannot be unambiguously classified as either EP or CP.

The years included in each composite are listed in Table 1. For figures which compare the emergence of nonlinearity in the composited response to moderate EP EN events as compared to extreme EP EN events, we weight the response in the extreme EP EN composite by its underlying Niño3.4 SST anomaly.

Most ENSO events peak in the early winter or late fall, and decay through the following spring. However, the lowerstratospheric response in observations (Manzini et al. 2006; Garcia-Herrera et al. 2006), in previous modeling studies (e.g. Cagnazzo et al. 2009), and in the model experiments described in this paper peaks in late winter, and hence we consider the response separately from December through February and for early spring (March and April).

Sudden stratospheric warming (SSW) events are defined according to the zonal wind reversals at $10 \mathrm{hPa}, 60 \mathrm{~N}$ following Charlton and Polvani (2007) and its corrigendum, and the corresponding observed events are as listed in Butler et al. (2014); we also explore sensitivity to using $10 \mathrm{hPa}$, $65 \mathrm{~N}$ zonal wind. For the observational SSW frequency we consider the extended period from 1958 to 2013. When considering the frequency of SSW during alternate phases of ENSO we include the reanalysis results of Polvani et al. (2017) who used the NOAA Climate Prediction Center (CPC) definition to identify ENSO events based on the ERSST version 4 dataset (see the Appendix). Split and displacement SSWs are computed as in Seviour et al. (2013), and the specific application of this algorithm to these GEOSCCM integrations is described in White et al. (2019).

Monthly anomalies are computed as follows. A monthly climatology over the full duration of each model experiment, reanalysis product, and observational dataset is computed, and is then subtracted from the raw fields to generate monthly anomalies. All anomalies are then detrended by removing the linear trend over the course of the simulated period. Daily anomalies are computed analogously, except that a daily climatology is used.

When considering differences between ENSO flavors and phases, we utilize two methodologies, and in all cases the null hypothesis is that the response to ENSO is linear. The first is a compositing approach, and statistical significance for the anomalies in a composite relative to climatology and for the difference between two composites is computed using a two-tailed Student $t$ test, unless otherwise specified. The compositing approach is applied to all three target questions.

The second is a regression approach, and we apply it to target questions 1 and 2 only. The SST anomalies in the Niño3.4 region during NDJF are used as a predictor for the extratropical response. We consider whether the response to $\mathrm{LN}$ is equal and opposite to that of EN by first computing the interaction term when both LN and moderate EN events are included in the same regression analysis ( $\mathrm{p} 220-228$ of McDonald 2014). If the slopes are found to be significantly different then regression lines for moderate $\mathrm{EN}$ and $\mathrm{LN}$ are plotted separately, however in practice the slopes are statistically indistinguishable for all figures in this paper. We therefore plot a single gray regression line for moderate EN and LN events. All LN events in this period were weaker than either extreme EN event, and so we only compare LN to moderate EN events. Statistical significance of the slope of the regression line is computed using a two-tailed Student t test.

We also consider whether the impact of extreme EN events is proportionately stronger than the response to moderate EN events by computing a linear best-fit and a polynomial best fit (e.g. $\mathrm{T}_{85 \mathrm{hPa} \text {, pole }} \sim a \times E N^{2}+b \times E N$ ) for all EN events, and then comparing the $R^{2}$ of the linear best-fit to the adjusted $R^{2}$ (Eq. 3.30 of Chatterjee and Hadi 2012) of the polynomial best fit. The adjusted $R^{2}$ takes into account the likelihood that a polynomial predictor will reduce the residuals by unphysically over-fitting the data. If the adjusted $R^{2}$ for the polynomial fit is less than the linear $R^{2}$, then a linear best-fit more succinctly describes EN's teleconnection.

Our results will highlight the ability of the large internal variability in the atmosphere to mask the response to ENSO. This large internal variability also makes it difficult to evaluate whether the model response to ENSO is realistic 
(Deser et al. 2017). However a necessary prerequisite for comparing observed and modeled ENSO teleconnections is for the model to realistically simulate a similar amount of variance as compared to that observed, as otherwise the model does not satisfactorily capture internal atmospheric variability (Deser et al. 2017). We therefore assess whether GEOSCCM simulates a realistic amount of variance for each metric considered in this paper in Appendix B.

\section{Changes in wave-driving}

We begin with composites of $500 \mathrm{hPa}$ geopotential height using the full ensemble for moderate EP EN, CP EN, extreme EP EN (97/98 and 82/83), and LN (Fig. 1). A comparable figure but for sea level pressure is included in Garfinkel et al. (2018b). All three EN composites show the canonical wavetrain pattern in the Western Hemisphere, with a low in the Northeastern Pacific, a high over Canada, and a low near the Eastern United States. Anomalies in the LN composite are nearly opposite to those in the EN composites. Each panel in Fig. 1 includes the $50 \mathrm{~m}$ contour of the climatological zonal wavenumber-1 (in green) and wavenumber-2 (in magenta) eddy height field in GEOSCCM. This field can be compared to the observed eddy height field in figure 2 in Garfinkel et al. (2010). GEOSCCM simulates realistic climatological stationary waves, though wave- 2 is too weak: its amplitude at $50 \mathrm{~N}$ at $500 \mathrm{hPa}$ is $75.3 \mathrm{~m}$ in GEOSCCM as compared to $87.5 \mathrm{~m}$ in MERRA.

We first focus on the modulation of wave- 1 by ENSO. As discussed in Garfinkel and Hartmann (2008) and Ineson and Scaife (2009), EN leads to low height anomalies over the North Pacific of the same sign as, and hence that constructively interfere with, the climatological stationary wave-1. moderate EP EI Nino

(a)

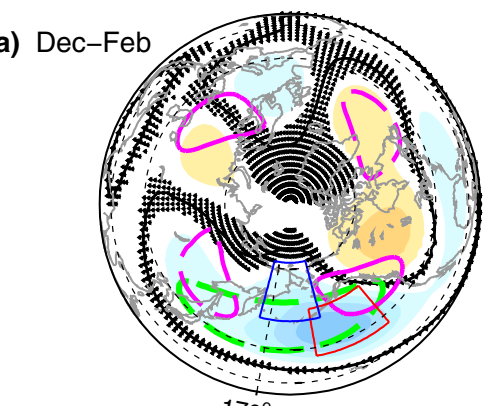

(b)

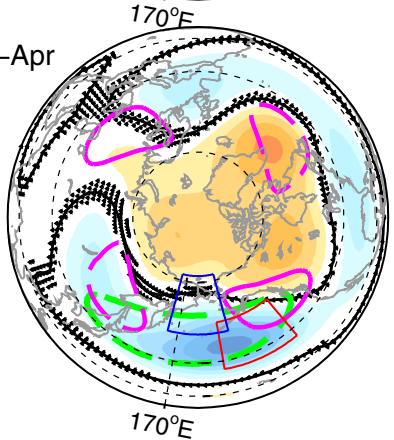

Geoptential height $(500 \mathrm{hPa})$ composites

\section{CP El Nino}

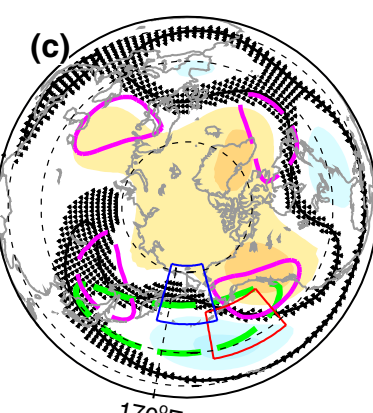
extreme EP El Nino
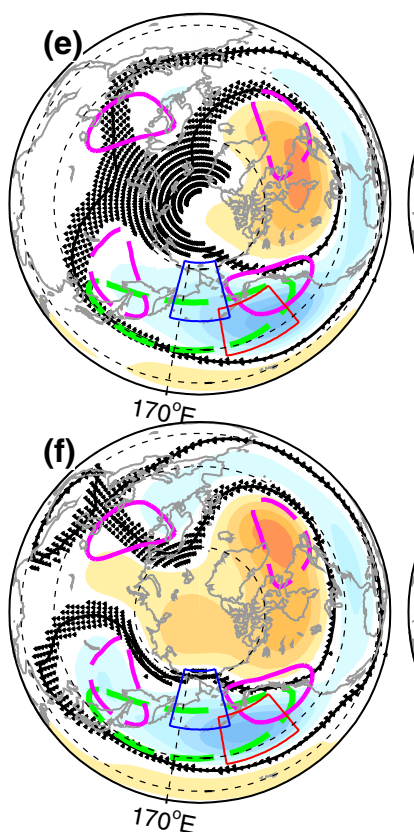
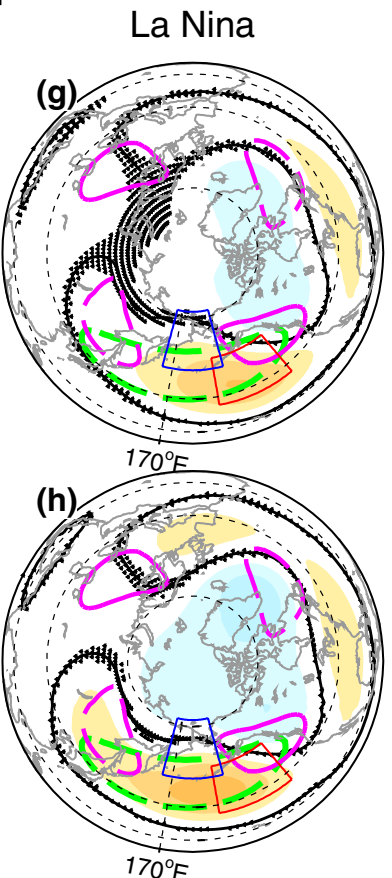
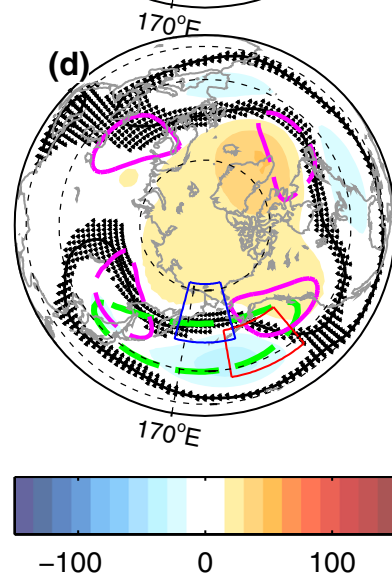

$\mathrm{m}$
Fig. 1 Geopotential height at $500 \mathrm{hPa}$ response to ENSO in GEOSCCM. The contour interval is $15 \mathrm{~m}$. A red box (from $35 \mathrm{~N}-55 \mathrm{~N}$, 190E-220E) demarcates the region in which the North Pacific response to ENSO peaks (as discussed in Garfinkel et al. (2018b)), while the blue box (from $52.5 \mathrm{~N}-72.5 \mathrm{~N}, 165 \mathrm{E}-195 \mathrm{E}$ ) demarcates the precursor region from Garfinkel et al. (2012) (see also Fig. 10). a, b moderate EP EN events: 1986/1987, 1991/1992; c, d CP EN events; e, f extreme EP EN: 1982/1983 and 1997/1998; g, h LN. (top) December through February and (bottom) March and April. The troughs and ridges of the $50 \mathrm{~m}$ contour climatological wavenumber-2 pattern are shown in magenta dashed and solid lines respectively, while the $50 \mathrm{~m}$ contour of the climatological wavenumber- 1 trough in the Pacific sector is shown in a dashed green line. Statistical significance is computed using a two-tailed Student's t test with a $95 \%$ confidence threshold using all 41 ensemble members, and stippling indicates grid boxes that are not significant using a false discovery rate of $10 \%$ following Wilks (2016) 
This effect is qualitatively similar for all three EN composites (Fig. 1). During LN, on the other hand, higher heights over the North Pacific lead to destructive interference (Ding et al. 2017). Previous work has linked these contrasting responses under EN and $\mathrm{LN}$ to opposite-signed anomalies in upward propagation of wave flux in the lower stratosphere (e.g. Garfinkel and Hartmann 2008). We diagnose changes in the upward wave flux into the lower stratosphere by the heat flux at $100 \mathrm{hPa}$ in Fig. 2 (Andrews et al. 1987). Specifically Fig. 2a shows the wave-1 heat flux response at 100 $\mathrm{hPa}$ for all ensemble members and all non-neutral ENSO events. Each event is stratified by its SST anomaly, and we indicate the range of responses across all 41 ensemble members (each ensemble member is a dot), the response in the MERRA reanalysis (a diamond), and the ensemble mean (a large $\mathrm{x}$ ). We then compute the linear best-fit regression line for moderate $\mathrm{EN}$ and $\mathrm{LN}$, and if the difference in slope between the regression line for moderate $\mathrm{EN}$ and $\mathrm{LN}$ is statistically significant, we list the slope separately for each. If the slopes are statistically indistinguishable, then one slope is quoted and only one line added.

There is no evidence to reject the null hypothesis that LN and EN have equal and opposite effects on wave-1 heat flux, as the slope of the best-fit lines for each are statistically indistinguishable despite hundreds of years of model output. Similarly, the response to extreme EN events is proportionately stronger than the response to moderate EP EN events, as the adjusted $R^{2}$ of the polynomial fit is smaller than the $R^{2}$ of the linear fit ( $R^{2}$ ratio is 0.9 ).
Do CP EN have a similar impact as EP EN events on wave-1? A compositing approach indicates that CP EN leads to significantly less wave-1 heat flux than moderate EP EN if we consider the entire 41-member ensemble by approximately a factor of two (Fig. 3a). Note that the North Pacific low is also weaker during CP EN (Fig. 1a as compared to Fig. 1c), and the tropical SST anomalies are weaker as well (Garfinkel et al. 2018b). How many CP EN events and EP EN events must be composited before the wave-1 heat flux in the lower stratosphere in winter becomes significantly different? To answer this question we introduce a bootstrapping methodology that will also be used in Sects. 5 and 6. We bootstrap with replacement the wave-1 heat flux response for a subsample of the full 41-member ensemble, with the size of the subsample increasing from 5 randomly selected events up to 75 randomly selected events for each ENSO composite. We create 2000 such bootstrapped subsamples for each subsample-size. We then compute the mean and the top and bottom $2.5 \%$ quantiles without making any assumption on the nature of the distribution, and hence form $95 \%$ confidence intervals of the response. This allows us to quantify how the uncertainty in the wave-1 response decreases as the number of events averaged together increases (Fig. 3a). The green line shows the difference between moderate EP $\mathrm{EN}$ and CP EN events, and the difference is significant when the green line does not touch the zero line. Approximately 35 individual events are necessary before the difference in wave-1 between moderate EP EN and CP EN events in Fig. 3a becomes statistically significant.

heat flux, detrended, (100hPa, 45N-85N)
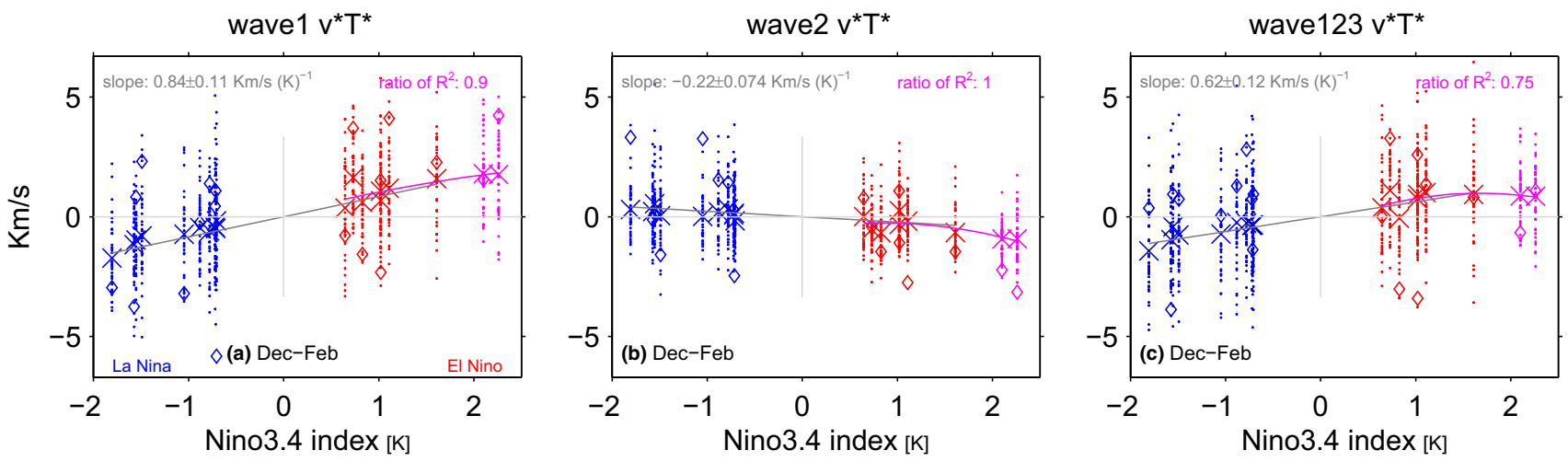

Fig. $2100 \mathrm{hPa}$ heat flux response to ENSO in winter (December through February). a Anomalies in zonal wavenumber-1 heat flux area-weighted from $45 \mathrm{~N}$ to $85 \mathrm{~N}$ stratified by SST anomalies in the Niño3.4 region, after the component of the variance linearly associated with the QBO at $50 \mathrm{hPa}$ and a linear trend has been removed; $\mathbf{b}$ as in (a) but for zonal wavenumber 2; c as in (a) but for the sum of wavenumbers 1,2 , and 3 . LN winters are in blue, moderate EN winters (whether EP, $\mathrm{CP}$, or marginal) are in red, and extreme EN winters are in magenta. A linear least-squares best fit is shown in each panel, and the slope is indicated. If the slope of the best fit is statistically significantly different for $\mathrm{LN}$ as compared to moderate EN, we show the slopes separately; if not, then a single slope and a single best-fit line is included. An additional polynomial best-fit is shown considering both moderate and extreme EN events in magenta. The ratio of the adjusted $R^{2}$ for the polynomial best-fit as compared to the $R^{2}$ for the linear best-fit is indicated in magenta. The ensemble mean response is indicated with a large $\mathrm{x}$, and each ensemble member with a dot. The response in MERRA reanalysis is shown with a diamond 
Fig. $395 \%$ confidence intervals on the response to ENSO when the full ensemble is subsampled. Heat fluxes in December through February for a wave-1, b wave- 2 , $\mathbf{c}$ the sum of wave numbers 1,2 and 3 . The response to $\mathrm{LN}$ is multiplied by -1 , and the magnitude of the response to extreme EP EN by the ratio of the magnitude of the Niño3.4 anomalies for the moderate EP EN composite and the extreme EP EN composite (which are $60 \%$ stronger during extreme EP EN than for the two moderate EP EN events)
$95 \%$ confidence intervals on the $100 \mathrm{hPa}$ heat flux response $[\mathrm{Km} / \mathrm{s}]$
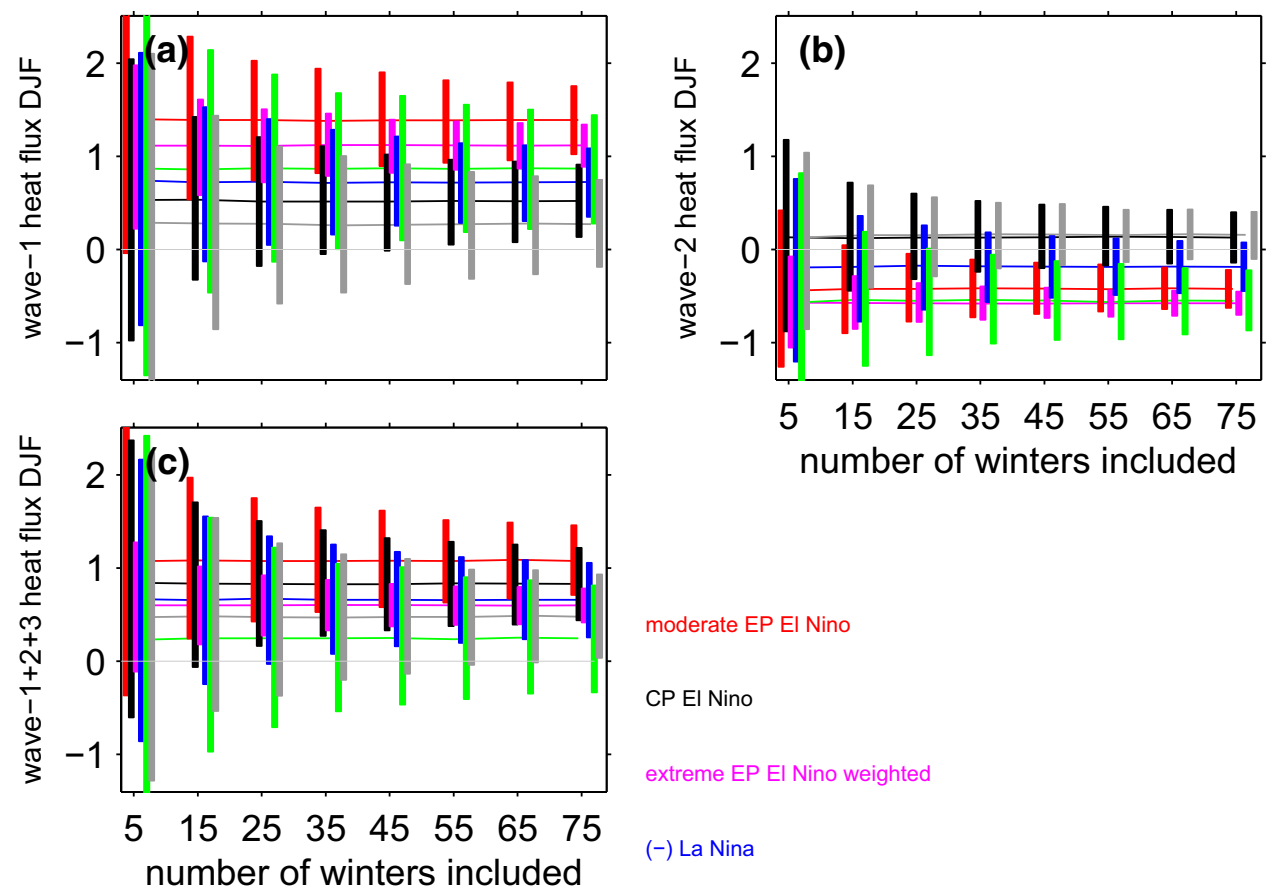

number of winters included moderate EP El Nino
CP EI Nino
extreme EP EI Nino weighted

(-) La Nina

moderate EP EI Nino-CP El Nino

moderate EP El Nino-extreme EP EI Nino

We next turn our attention to wave- 2 . The climatological wave-2 field is composed of a ridge over the West Coast of North America and a trough over Northeast Asia (Fig. 1), and the North Pacific trough in response to moderate EP EN and extreme EN destructively interferes with this North American ridge (consistent with e.g. Taguchi and Hartmann 2006; Garfinkel and Hartmann 2008). CP EN, in contrast, leads to constructive interference with this ridge (Fig. 1). As discussed in Garfinkel et al. (2018b), the North Pacific trough associated with $\mathrm{CP}$ EN is characterized by a higher zonal wavenumber due to the details of how CP EN modulates tropical convection, and hence the North Pacific trough does not reach the far-Northeastern Pacific. The net effect is that the Canadian ridge during CP EN overlies the climatological wave- 2 ridge. Approximately 30 individual events are necessary before the difference in wave- 2 between EP EN and CP EN becomes statistically significant (green lines on Fig. 3b). No other nonlinearities are evident for wave-2: the response to $\mathrm{LN}$ events is equal and opposite as compared to EN events (the slopes of the best-fit linear lines for LN and moderate EN are statistically indistinguishable), and the response to extreme EN events is somewhat more than proportionately stronger than the response to moderate EP EN events, though there is little statistical justification for preferring a polynomial fit as the adjusted $R^{2}$ of the polynomial fit is similar to the $R^{2}$ of the linear fit ( $R^{2}$ ratio is 1.0 ).
The total planetary wave heat flux (defined here as wavenumbers 1 through 3) at $100 \mathrm{hPa}$ is shown in Fig. 2c. The response to $\mathrm{LN}$ events is equal and opposite as compared to EN events of comparable magnitude. While the response to extreme EN events is not quite proportionately stronger than the response to moderate EP EN events, there is little statistical justification for preferring a polynomial fit given the adjusted $R^{2}$ of the polynomial fit. The location of the maximum SSTs also appear to lead to a slightly different response: as a consequence of the difference in wave-2, the total planetary wave heat flux is robustly different for EP EN as compared to CP EN events (Fig. 3c). Specifically, the enhanced wave-1 heat flux during both EP EN and CP EN events is partially compensated by reduced wave- 2 for EP EN events, but dominates the net effect during CP EN events. As to the salience of this nonlinearity, the green lines on Fig. 3c show that there is no significant difference between the total heat flux response to moderate EP EN as compared to CP EN even if 75 events are considered. The gray line on Fig. $3 \mathrm{c}$ indicates the difference in planetary wave heat flux between moderate and extreme EP EN events, after the response for the extreme EP EN events has been weighted by the ratio of the Niño3.4 index for the two composites. A robust nonlinearity between moderate and extreme EP EN events can be identified when the gray line does not cross the zero-line. We find that $\sim 65$ moderate and 
Fig. 4 As in Fig. 2 but for the stratospheric response to ENSO in boreal winter and spring. $\mathbf{a}, \mathbf{b}$ Anomalies in 85-hPa temperature area-weighted from $70 \mathrm{~N}$ to the pole, after the component of the variance linearly associated with the QBO at $50 \mathrm{hPa}$ has been removed; $\mathbf{c}, \mathbf{d}$ as in a, b but for zonal mean zonal wind at $10 \mathrm{hPa}$ and $60 \mathrm{~N}$. (top) December, January, and February; (bottom) March and April

\section{Stratospheric response to ENSO}
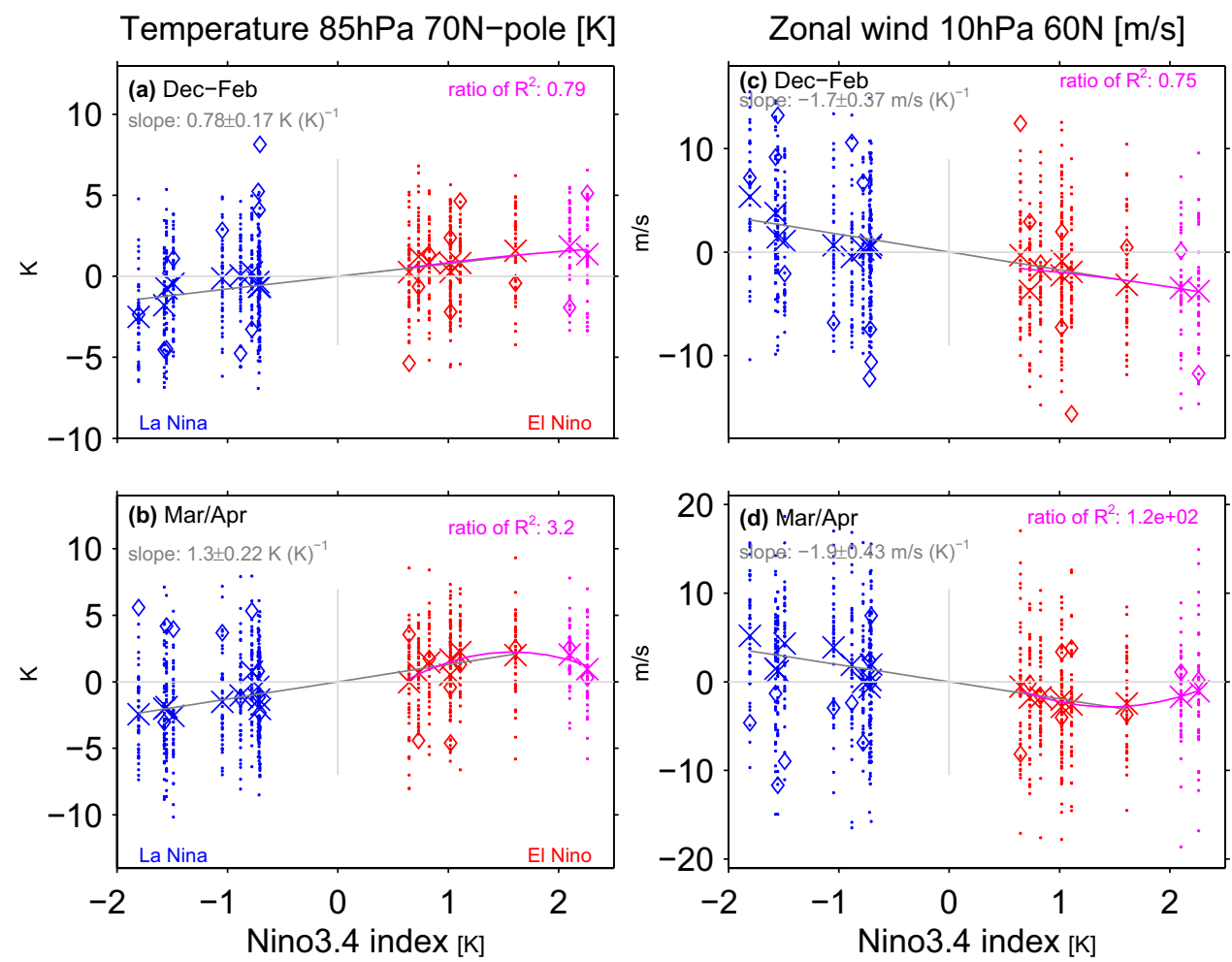

extreme events must be composited before the relative weakness of heat flux for extreme EN events becomes robust.

In conclusion, the wavenumber composition of the upward flux is dependent on the flavor of the EN event. The responses to $\mathrm{LN}$ and $\mathrm{EN}$ are symmetric, and the response to extreme EN is essentially proportionately stronger than the response to moderate EN events, in our GEOSCCM ensemble. The implications in the stratosphere for these changes in the wave-driving are discussed in the next section.

It is important to note that in all panels of Fig. 2, there is substantial intra-ensemble variability. The winter stratosphere is characterized by unforced internal variability, and consistent with this more than 30 events are needed to identify differences in the response to moderate EP EN and CP $\mathrm{EN}$ in Fig. 3a, b. Hence the anomalies in a given winter can be opposite in sign to the forced response as deduced from the ensemble mean.

\section{Changes in the Arctic stratosphere}

We now turn our attention to the linearity of the stratospheric response. Figure $4 \mathrm{a}$, b consider the temperature response in the lower stratosphere during December through February and during March and April, respectively, and Figure $4 \mathrm{c}, \mathrm{d}$ consider the zonal mean zonal wind response at
$60 \mathrm{~N}$ and $10 \mathrm{hPa}$. The responses to $\mathrm{EN}$ and $\mathrm{LN}$ are equal in magnitude and opposite in sign, as the slope of the linear best-fits for EN events and for LN events are statistically indistinguishable.

The Arctic stratospheric response depends linearly on the strength of the EN event during winter (Fig. 4a), as the strongest EN events lead to a proportionately stronger polar warming and vortex weakening, though during spring the ensemble mean response to the two strongest EN events falls below the linear best-fit line, and a polynomial fit is preferred. How many events are needed to robustly establish that in spring, extreme EN events may not have an impact on the Arctic stratosphere proportionate with the magnitude of SST anomalies in the tropical Pacific? Figure 5 is similar to Fig. 3 except that it focuses on the stratospheric metrics. During winter, there is no significant difference between extreme and moderate EP EN even if 75 events are considered as the gray line crosses the zero line. In contrast, during spring nonlinearities are evident if more than 45(65) events are considered in Fig. 5c (Fig. 5d): the response to moderate $\mathrm{EP} \mathrm{EN}$ is larger than the response to extreme events after weighting the response in the extreme events composite by the magnitude of the underlying events.

In DJF, EP EN has a stronger effect on zonal wind at $10 \mathrm{hPa}, 60 \mathrm{~N}$ than $\mathrm{CP} \mathrm{EN}$, and the difference becomes statistically significant if more than 65 events are taken, consistent 
Fig. 5 As in Fig. 3 but for the stratospheric response to ENSO a polar cap $(70 \mathrm{~N}$ and poleward area weighted) temperature at $85 \mathrm{hPa}$ in December through February; b zonal mean zonal wind at $10 \mathrm{hPa}$ and $60 \mathrm{~N}$ in December through February; c, $\mathbf{d}$ as $\mathbf{a}$ and $\mathbf{b}$ respectively but for March and April

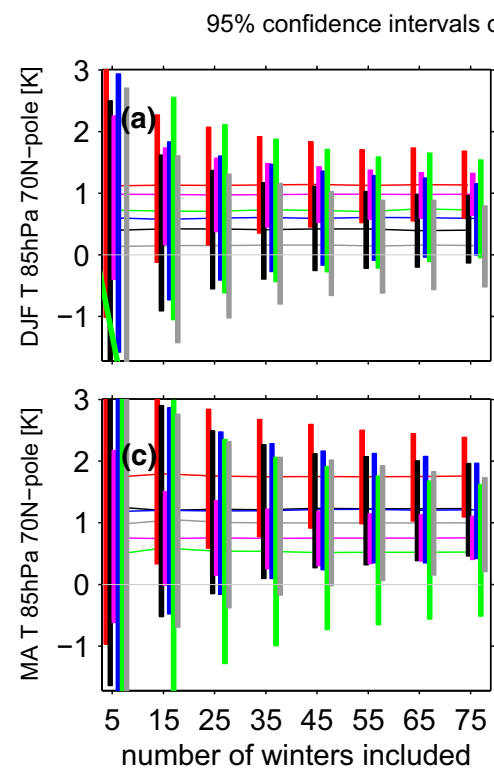

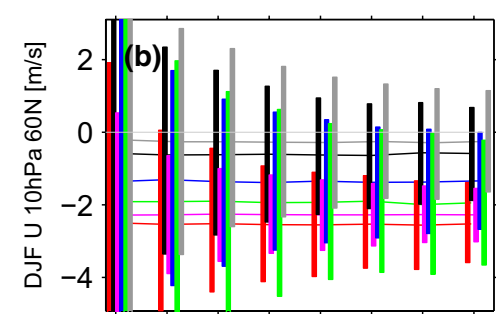

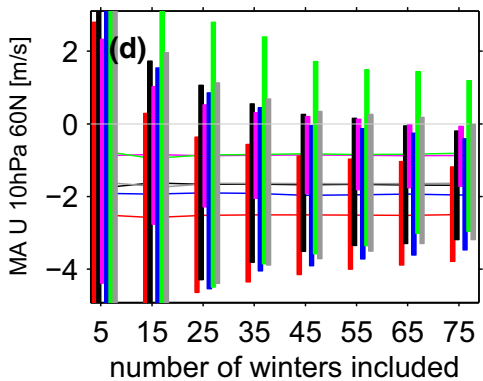

moderate EP EI Nino

CP EI Nino

extreme EP El Nino weighted (-) La Nina with Garfinkel et al. (2013); Iza and Calvo (2015) (Fig. 5c). Note that the response to CP EN as compared to climatology (black line) is insignificant in the DJF average, as the CP $\mathrm{EN}$ vortex response develops only in late winter (consistent with Garfinkel et al. (2013)). In spring, on the other hand, no robust difference between EP and CP EN is apparent, also consistent with Garfinkel et al. (2013).

\section{Changes in subpolar surface climate}

It is well established that Arctic stratospheric anomalies can propagate down to the surface (Baldwin and Dunkerton 1999; Charlton et al. 2003; Baldwin et al. 2003; Kidston et al. 2015; White et al. 2019), and we now consider the linearity of the surface impacts of ENSO in subpolar latitudes. Figure 6a, b shows the polar cap sea level pressure response to ENSO. The response to $\mathrm{LN}$ is equal and opposite to that of EN in both winter and spring. The response to extreme EN events is proportionately larger than the response to moderate EN events in winter though not in spring, consistent with the seasonality evident in the stratosphere. The gray line in Fig. 7c considers the robustness of this nonlinearity between extreme and moderate EN events in spring. The gray line in Fig. $7 \mathrm{c}$ does not touch the zero line after $\sim 35$ events are considered so that the extreme events response is not proportionately larger than the response to moderate events. There is no difference in the response to $\mathrm{CP} \mathrm{EN}$ as compared to EP EN in both midwinter and spring as the green lines cross the zero line in Fig. 7a, c, largely mirroring the stratospheric response.
One of the strongest impacts of a change in the Arctic Oscillation is cooling over Northern Eurasia (Thompson et al. 2002; Garfinkel et al. 2017; Kretschmer et al. 2018), and Figs. $6 c, d$ and $7 b, d$ consider the impact of ENSO on near surface temperature anomalies over land areas in Eurasia poleward of $44 \mathrm{~N}$. The Eurasian surface temperature response to $\mathrm{LN}$ is equal and opposite to that of moderate $\mathrm{EN}$, but the response to strong EN events is not proportionately larger. A compositing perspective on the emergence of nonlinearities is shown on Fig. 7: During winter (Fig. 7b) the response is linear, but in spring (Fig. 7d) in contrast the gray line does not touch the zero line if more than 50 events are considered. There is a discrepancy between the two methods in DJF, as the compositing approach does not identify any nonlinearity between moderate and extreme EN but the regression approach does; however the two events included in the extreme EN composite differ as to the degree of nonlinearity, with only one featuring a response much weaker than the linear best-fit based on moderate EN events. Hence it is worth revisiting this discrepancy for future work after more extreme EN events have occurred.

$\mathrm{EP}$ and $\mathrm{CP}$ events have an indistinguishable impact on Eurasian surface temperatures in midwinter, though in spring the impact of $\mathrm{CP}$ events is somewhat stronger if more than 35 events are considered (i.e. the green line does not touch the zero line in Fig. 7d). This difference between CP and EP may reflect a tropospheric route for $\mathrm{CP}$ to affect Eurasian surface temperatures, as differences between $\mathrm{CP}$ and EP in spring of Arctic sea level pressure and in the stratosphere are weak. 
Fig. 6 As in Fig. 4 but for the surface response to ENSO a, b sea level pressure from $80 \mathrm{~N}$ and poleward; c, d $2 \mathrm{~m}$ temperatures over land areas in Eurasia area-weighted from $44 \mathrm{~N}$ and poleward

Fig. 7 As in Fig. 3 but for a, c sea level pressure from $80 \mathrm{~N}$ and poleward; $\mathbf{b}, \mathbf{d}$ for two meter temperatures over land areas in Eurasia area-weighted from $44 \mathrm{~N}$ and poleward

\section{Surface response to ENSO}
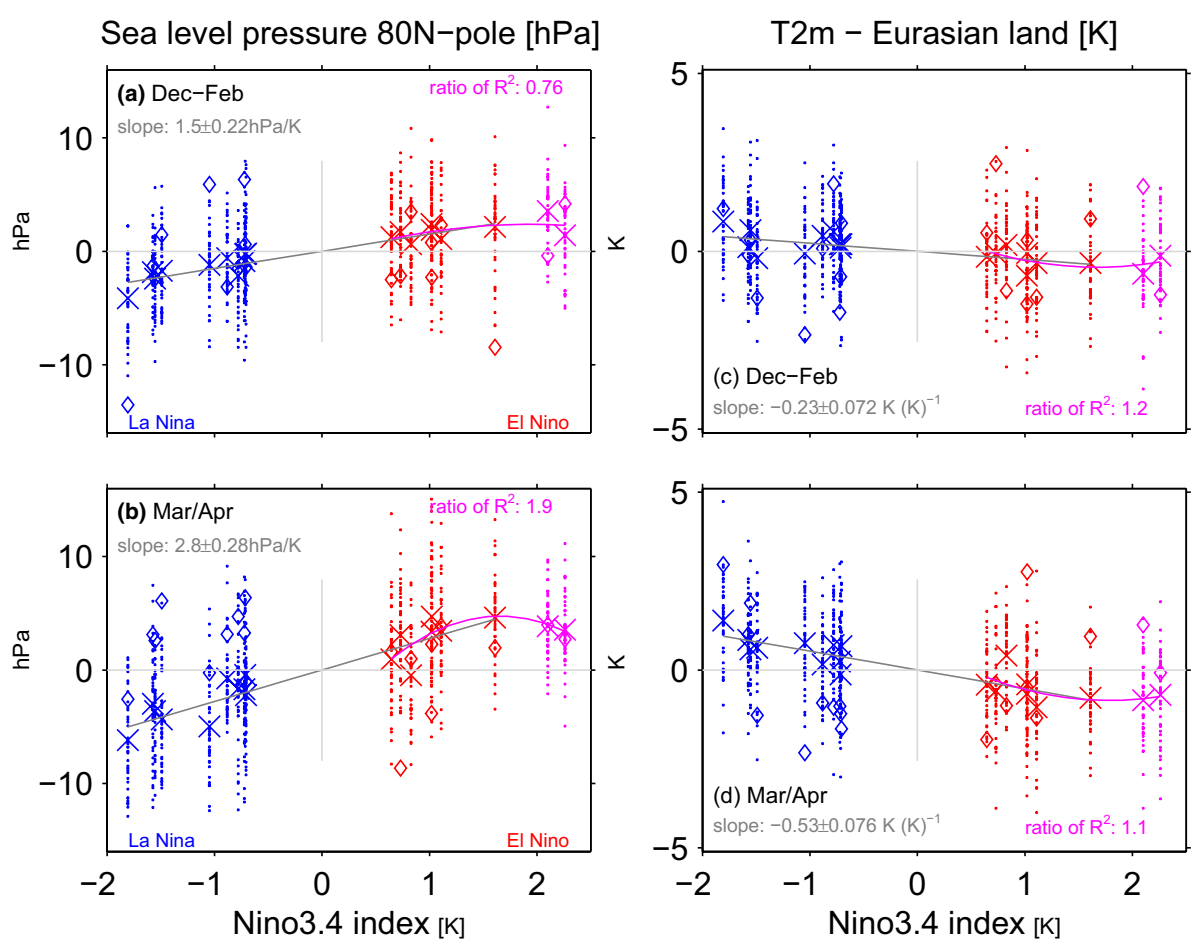

$95 \%$ confidence intervals on the surface response
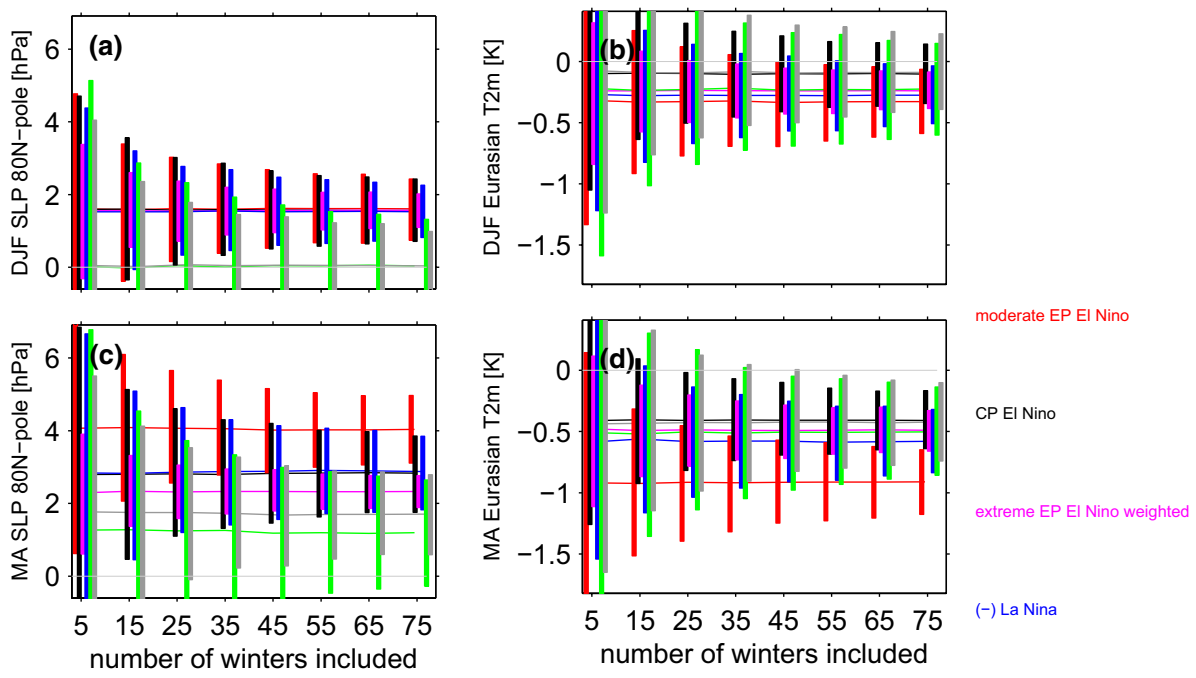

moderate EP EI Nino-CP El Nino

\section{Frequency of SSW occurrence}

Thus far we have focused on the seasonal mean response to ENSO, and we now turn our attention to changes in SSW frequency and morphology in response to ENSO.
We consider two different aspects of the SSW response to ENSO: differences in morphology between EP EN and CP $\mathrm{EN}$, and the frequency of SSW during LN. 


\subsection{Morphology of SSW during EP EN and CP EN}

Section 4 highlighted the difference in the zonal wavenumber composition of the wave flux at $100 \mathrm{hPa}$ between EP $\mathrm{EN}$ and CP EN, and we now show that this difference has implications for the morphology of SSWs. Specifically, there are differences in the relative frequency of split versus displacement SSWs for CP EN as compared to both moderate and extreme EP EN events. The frequency of split and displacement SSWs is shown in Table 2. Displacements

Table 2 Frequency of splits and displacement SSWs for CP EN and EP EN events

\begin{tabular}{lll}
\hline & \multicolumn{2}{l}{ Frequency of SSWs } \\
\cline { 2 - 3 } & Split & Displacement \\
\hline Climatology & 0.25 & 0.32 \\
Moderate EP EN & 0.31 & 0.53 \\
Extreme EP EN & 0.26 & 0.50 \\
CP EN & 0.36 & 0.30
\end{tabular}

Displacements are clearly preferred for EP EN events, while splits are slightly enhanced in both EP EN and CP EN as compared to climatology are clearly preferred for EP EN events, while splits are slightly enhanced in both EP EN and CP EN as compared to climatology.

The binomial theorem can be used to evaluate the statistical significance of the respective changes in SSW frequency for each EN flavor, and the increase in displacement events for moderate EP EN and split events for CP EN is robust ( $\mathrm{p}=9 \mathrm{e}-5$ for displacement during moderate EP EN, and $p=0.02$ for splits during CP EN). These changes in SSW morphology are consistent with the changes in the zonal composition of the wave-driving discussed in Sect. 4.

\subsection{Revisiting the La Nina-SSW relationship}

As discussed in the introduction, $\mathrm{LN}$ does not lead to a reduction in observed SSW frequency as compared to e.g. neutral ENSO. In apparent contrast, for all metrics evaluated in this paper we were unable to detect any deviations from linearity in the seasonal mean response to LN. Is the response to LN in GEOSCCM inconsistent with the observed response to $\mathrm{LN}$ ?

Figure 8 shows a histogram of the SSW frequency in each ENSO phase for each member of our ensemble. Figure 8 a focuses on EN years, with each member in our 41
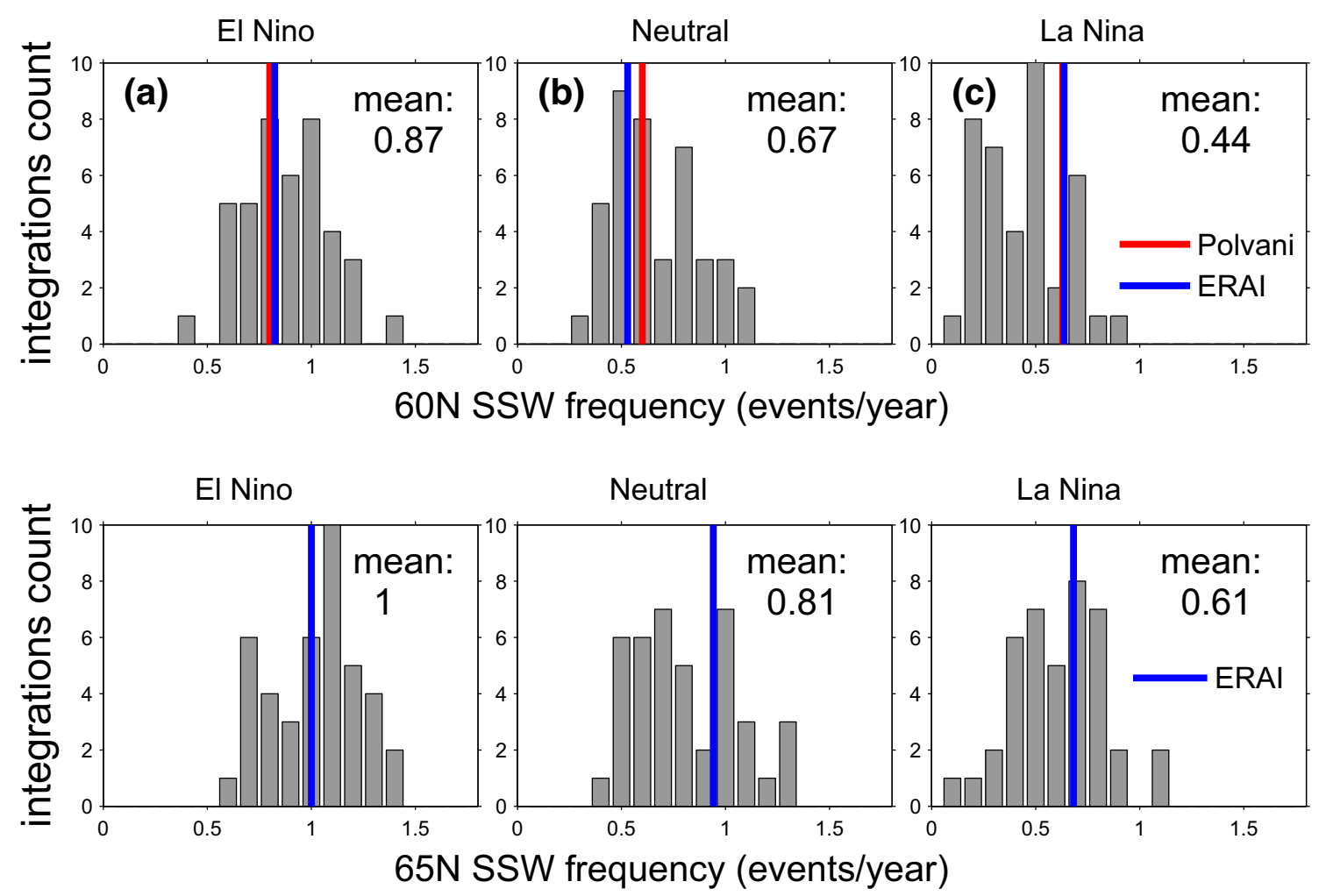

Fig. 8 Histograms of SSW frequency across all the ensemble members during EN (left), neutral (center) and LN (right) years. Reanalysis frequencies in colors: Polvani et al. (2017) frequency in red and our reanalysis frequency in blue. The top panel defines SSWs using wind reversals at $60 \mathrm{~N}$, while the bottom panel defines SSWs using wind reversals at $65 \mathrm{~N}$ 
member ensemble treated separately, and for simplicity we do not differentiate between EP and CP events in this subsection. The $\mathrm{x}$-axis shows the frequency of SSWs per year, and the y-axis shows how many ensemble members simulate that frequency. The colored vertical lines show reanalysis frequencies: The frequency of 0.8 events per EN year from Polvani et al. (2017), and the reanalysis frequency if we apply our ENSO classification algorithm to observations in blue at 0.78 events per EN year. We first consider the distribution of SSW frequency using zonal wind at $60 \mathrm{~N}$ (top row). There is large variability across the ensemble, with some ensemble members indicating e.g. more than 1.2 SSW per EN winter while others indicate a frequency less than half of this. The response to $\mathrm{LN}$ is similarly varied (Fig. 8c), with some ensemble members indicating that LN leads to more SSW than the climatological average in GEOSCCM of 0.61 per winter (White et al. 2019), while others indicate that LN nearly shuts down SSW occurrence. Overall, however, EN leads to more SSW while LN results in fewer SSWs, as compared to neutral ENSO (Fig. 8b). However, some ensemble members have similar SSW frequency during $\mathrm{LN}$ and $\mathrm{EN}$, i.e LN/EN SSW frequency ratio close to one. Specifically, 5 ensemble members have a LN/ EN ratio of 0.9 and another ensemble member has a ratio of 1.05; hence, $14 \%$ of the ensemble members simulate SSW frequencies for EN and LN that are within 10\%. Results are similar if zonal winds at $65 \mathrm{~N}$ (bottom row) are used to define SSW events, therefore in the rest of this work we use the $60 \mathrm{~N}$ definition only.

The relative frequencies of SSW during each ENSO phase is consistent with the North Pacific teleconnections for each ENSO phase, if one computes the ensemble mean response for each winter. As discussed in Sect. 4, an anomalously deep low in the Northwest Pacific can constructively interfere with the climatological stationary waves and lead to enhanced wave-driving. Garfinkel et al. (2012) found that a deepened low in this region is also associated with SSW events in response to ENSO. Figure 9 contrasts the $500 \mathrm{hPa}$ height anomaly in the SSW precursor region (as defined by Garfinkel et al. (2012), see the blue box on Fig. 1) for each winter season averaged across all ensemble members, with the frequency of SSW events for each winter season averaged across all ensemble members. LN years are marked with blue dots, EN years with red dots and neutral ENSO years with green dots. The two metrics are clearly related $(\mathrm{r}=-0.72)$, such that years with ridging in this region are associated with fewer SSW events, while troughs lead to increased SSW frequency. The correlation is highly statistically significant, and the EN winters and LN winters do not overlap in either metric.

In individual ensemble members, however, the frequency of SSW during EN winters and LN winters is similar, while others show almost no SSW during LN winters. What can

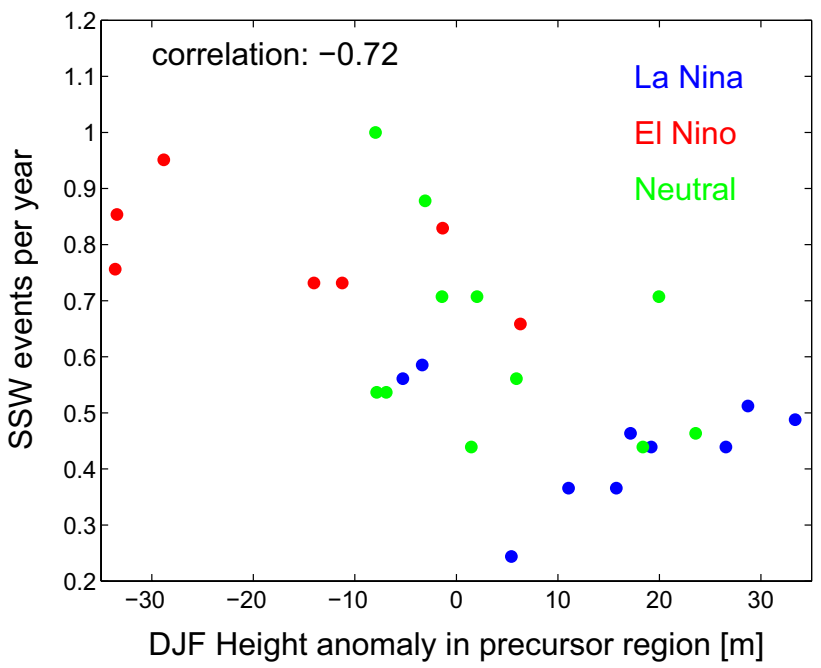

Fig. 9 The frequency of SSWs (y axis) for each winter season averaged across all ensemble members against height anomaly at $500 \mathrm{hPa}$ during each winter season (defined here as December through February) in the precursor region ( $\mathrm{x}$ axis). This region is defined as in Garfinkel et al. (2012) and is shown with a blue box on Fig. 1. LN years are indicated with blue dots, EN years are indicated with red dots and neutral ENSO years are indicated with green dots

account for the large spread in SSW frequencies across the ensemble members? We consider which aspect(s) of the ENSO teleconnection are related to the spread in the SSW response across the ensemble in Figs. 10 and 11. Figure 10a considers whether the spread in SSW frequency in our ensemble can be related to variability in the SSW precursor region. To quantify the strength of ENSO teleconnections in the SSW precursor region we compute the frequency of days in December through February in which the height anomaly at $500 \mathrm{hPa}$ is more negative than $-80 \mathrm{~m}$ meters (x-axis), and results are not sensitive to $\sim 30 \%$ changes to this threshold. The frequency of SSWs during LN winters is divided by the frequency of SSWs for EN winters and the ratio is shown on the $y$-axis. Each dot represents a single ensemble member. There is a clear relationship between these parameters: in ensemble members in which the frequency of subpolar Northwest Pacific extreme lows does not depend on ENSO phase, SSW frequency also does not depend on ENSO phase. In contrast, in ensemble members in which EN leads to more frequent strong troughs in this region as compared to LN, SSW frequency is reduced during $\mathrm{LN}$ as compared to EN. Overall, these two metrics are significantly correlated at the $95 \%$ confidence level using a Student's test $(r=0.48)$.

As discussed in Garfinkel et al. (2018b), the difference in height anomalies between EN and LN peaks in the gulf of Alaska and not in the precursor region. Is there a relationship between height anomalies in the Gulf of Alaska 


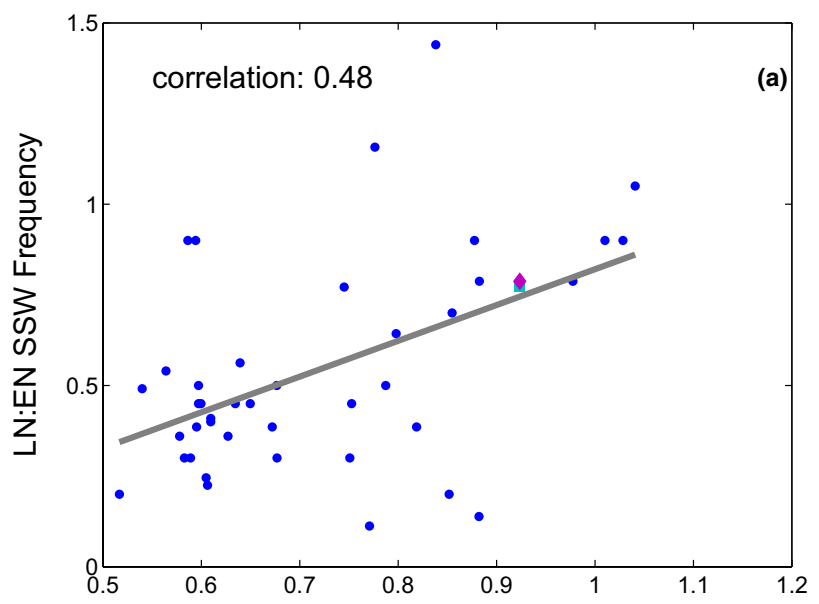

LN:EN precursor region extreme height days

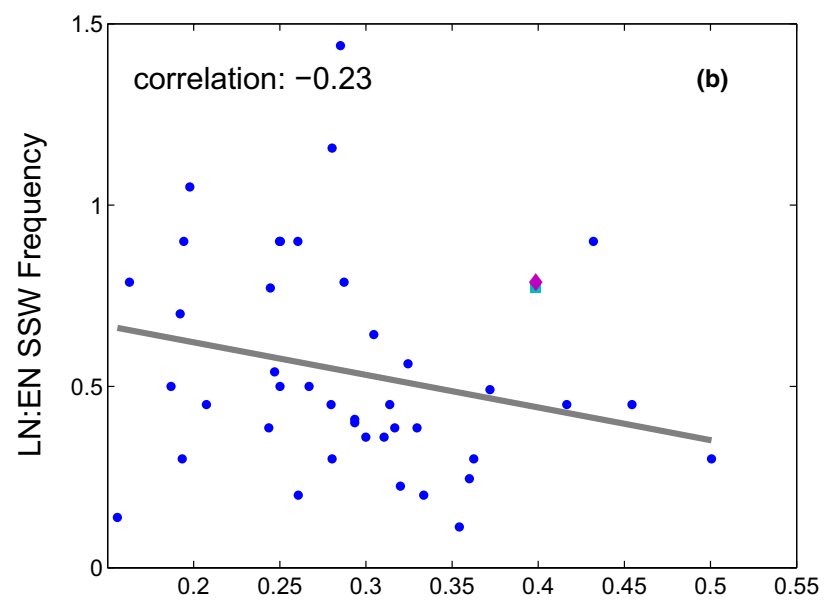

$\mathrm{LN}$ :EN gulf of Alaska extreme height days

Fig. 10 The relation between SSW frequencies and extreme height days (definition in the text) during ENSO winters during December through February in a the precursor region, $\mathbf{b}$ the gulf of Alaska (shown with a red box on Fig. 1). The frequency of SSWs in LN winters divided by the frequency in EN winters is shown in the y-axis. The dots denote GEOSCCM results. The square and diamond show the reanalysis result using our ENSO definition and that of Polvani et al. (2017), respectively, with the location of the markers on the $\mathrm{x}$-axis based on defining ENSO seasons by the NDJF seasonal mean

and ENSO SSW frequency? We consider this question in Fig. 10b, which compares SSW frequencies and the strength of ENSO teleconnections on $500 \mathrm{hPa}$ geopotential height in the gulf of Alaska (see the red square on Fig. 1) for each ensemble member. We see that in spite of the strong tropospheric influence of ENSO on the Gulf of Alaska, there is no relationship between the ENSO impact on the Gulf of Alaska and the ENSO impact on SSW frequency (consistent with Garfinkel et al. 2012).

We next consider the relationship between the effect of ENSO on SSWs and on seasonal mean polar stratospheric

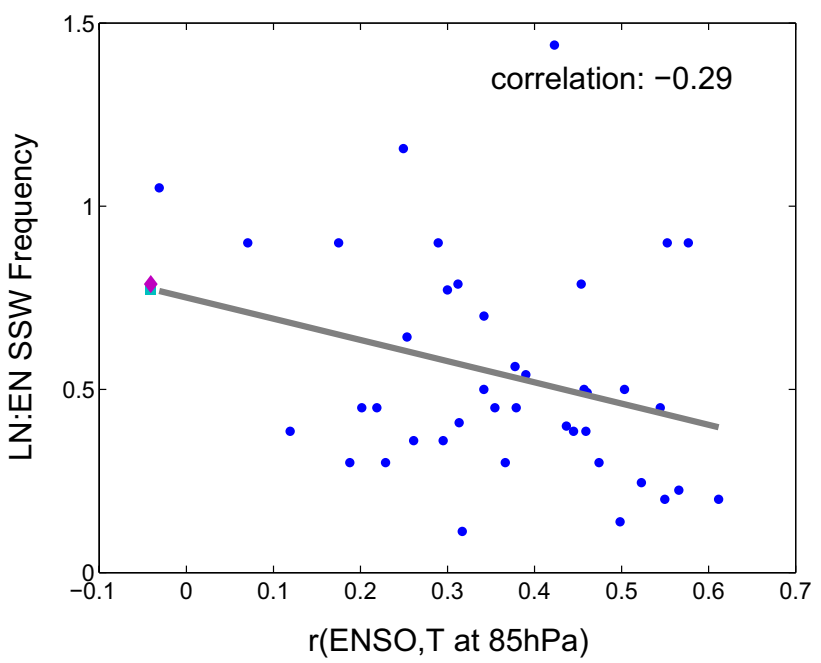

Fig. 11 The y-axis is similar to Fig. 10. The $\mathrm{x}$ axis shows the correlation between Niño3.4 index and temperature anomalies at $85 \mathrm{hPa}$ area weighted from $70 \mathrm{~N}$ and poleward during December through March

temperatures. One might expect a close relationship between the effect of ENSO on the seasonal mean stratospheric state and on SSWs, and that an ensemble member with a weaker seasonal mean stratospheric vortex during LN must necessarily have a larger frequency of SSW during LN. To examine this, Fig. 11 compares the relationship between ENSO and polar cap temperatures at $85 \mathrm{hPa}$ in DJFM (x-axis) with the relationship between ENSO and SSW frequency (y-axis). We see that ensemble members with a weaker correlation between ENSO and Arctic stratospheric temperatures (i.e., r small) simulate higher LN SSW frequency as compared to EN (i.e., LN/EN larger). This relationship is not statistically significant however (correlation -0.29), and individual ensemble members do not necessarily show this behavior. Some ensemble members show correlations between ENSO and Arctic stratospheric temperatures in the seasonal mean that exceed 0.5 yet roughly equal EN and LN SSW frequencies. Results are similar if we compare the seasonal mean correlation of the Niño3.4 index and zonal wind anomalies at $10 \mathrm{hPa}$ and $60 \mathrm{~N}$ with the relationship between ENSO and SSW frequency: the correlation across all ensemble members is 0.33 . Hence, while the seasonal mean response and SSW response are related, one should not be surprised to find periods when this connection breaks down.

\section{Discussion and conclusions}

It is well established that the El Niño Southern Oscillation (ENSO) impacts the global atmospheric circulation in the stratosphere (Domeisen et al. 2019), and specifically El Niño leads to warmer Arctic temperatures by several Kelvin on 
average (Sassi et al. 2004; Garcia-Herrera et al. 2006; Garfinkel and Hartmann 2007; Camp and Tung 2007; Free and Seidel 2009).

Here we considered whether the responses to EN and $\mathrm{LN}$ are equal in magnitude and opposite in sign. Each EN event also differs in both the location and magnitude of maximal sea surface temperature (SST) anomalies (Capotondi et al. 2015), and it is unclear whether these differences in the SST pattern are crucial for the stratospheric response. We specifically are interested in whether the response is proportional for moderate vs extreme EN events, and to what extent the response to EN depends on the precise location of maximal temperature anomalies. The main conclusions of this study are listed in Table 3 and summarized as follows:

1. EP EN leads to enhanced wave-1 but reduced wave-2 in the lowermost stratosphere, while CP EN leads to a more moderate increase in wave- 1 but not reduced wave-2 (Figs. 2, 3). This leads to a difference in the morphology of SSW forced by each ENSO flavor: EP EN have a preference for displacement events as compared to CP EN (Table 2). This difference in the zonal wavenumber composition can be linked back to the North Pacific teleconnection associated with each EN flavor, which in turn is associated with differences in the zonal wavenumber of the tropical convection (Garfinkel et al. 2018b).

2. The composited response in the Arctic stratosphere for EP EN events is stronger than for CP EN events in winter but not spring.

3. The Arctic stratospheric response and surface response to extreme EN events is somewhat weaker than one might have expected if the response was linear in the amplitude of the EN event, with deviations from linearity more pronounced in spring than in winter.

4. There is no indication of any nonlinearities in the wave driving or in the Arctic response to EN as compared to $\mathrm{LN}$, and EN leads to more SSWs while $\mathrm{LN}$ leads to fewer SSWs in the ensemble mean (Fig. 8). In approximately $14 \%$ of the ensemble members, however, there is little difference in SSW frequency between EN and LN (Fig. 10) and in some ensemble members, the SSW frequency during $\mathrm{LN}$ approaches 1 event per year, suggesting that a similar SSW frequency for both EN and $\mathrm{LN}$ can occur by chance if a relatively short sample is considered. Hence it is premature to conclude from the observational record that $\mathrm{LN}$ does not lead to reduced SSW frequency, due to internal atmospheric variability. That being said, intra-ensemble variability in LN SSW frequency can be related back to intra-ensemble variability in the tropospheric response to LN.

In all regions, at least 25 events in each composite are necessary before nonlinearities can be identified as statistically significant at the $95 \%$ confidence level, and the nonlinearities that emerge fastest from the noise are between different flavors of EN events rather than between EN and LN. In contrast, nonlinearities in the tropospheric response were salient with far fewer events (Garfinkel et al. 2018b). Given that only approximately $20 \mathrm{EN}$ events and $14 \mathrm{LN}$ events are considered in the observational studies of Yu et al. (2012) and Deser et al. (2017) several of which occurred before the start of regular radiosondes throughout the Arctic in 1957, it is not surprising that it has been difficult to establish conclusively the nature of nonlinearities using observational data.

Table 3 A summary of nonlinearities in the response to ENSO, including the number of events that must be averaged in order for the nonlinearity to become statistically significant for a compositing approach

\begin{tabular}{llll}
\hline Summary of nonlinearities & & & \\
\hline Region & EN vs LN & Extreme EN vs. moderate EN & $\begin{array}{l}\text { EP vs CP (only } \\
\text { composite rel- } \\
\text { evant) }\end{array}$ \\
\hline v'T' $100 \mathrm{hPa}$, wave-1 & Linear & Linear & $>35$ events \\
v'T' $100 \mathrm{hPa}$, wave-2 & Linear & Linear & $>25$ events \\
v'T' $100 \mathrm{hPa}$, wave 1-3 & Linear & $>65$ events for composite, linear for regression & Linear \\
T85 hPa, 70N-pole, DJF & Linear & Linear & Linear \\
T85 hPa, 70N-pole, MA & Linear & $>45$ events for composite, nonlinear for regression & Linear \\
U10 hPa, 60N, DJF & Linear & Linear & $>65$ events \\
U10 hPa, 60N, MA & Linear & $>75$ events for composite, nonlinear for regression & Linear \\
SLP $80 \mathrm{~N}$-pole, DJF & Linear & Linear for composite, linear for regression & Linear \\
SLP $80 \mathrm{~N}-$ pole, MA & Linear & $>35$ for composite, nonlinear for regression & Linear \\
T2m Eurasia land, DJF & Linear & Linear for composite, nonlinear for regression & Linear \\
T2m Eurasia land, MA & Linear & $>45$ for composite, nonlinear for regression & $>35$ events \\
\hline
\end{tabular}


Stated another way, there is substantial internal variability in the polar stratosphere that masks any true nonlinearities and leads to a small signal to noise ratio; this internal variability may also alias as apparent nonlinearities (e.g., the similar SSW frequencies during EN and $\mathrm{LN}$ ) when none in fact may exist.

Our conclusions are based on an ensemble of GEOSCCM integrations forced with observed SSTs over the period 1980 to 2009. Such an ensemble enables an apples-to-apples comparison to the observed response to ENSO in a given season as compared to model integrations with annually repeating identical SST anomalies (as analyzed by Garfinkel et al. 2013; Rao and Ren 2016b), idealized SST patterns (Hegyi et al. 2014), or SST anomalies developed in coupled oceanatmosphere models (Calvo et al. 2017). However we recognize three limitations of our approach:

1. The configuration used here violates energetic constraints, and does not allow for the generation of selfconsistent SST anomalies and surface teleconnections.

2. SST anomalies are imposed globally, and hence it is possible that SST anomalies outside of the tropical Pacific are responsible for some of the stratospheric response. It is also reasonable to ask whether the extratropical response in our composites is the result of a single outlier included in a given composite, and is not truly representative of the other members in that composite. Furthermore, our experiments only extend for thirty years, and cannot be extended to include observed events that occurred before 1980 or since 2010. Figures 2, 4, and 9 indicate that these potential complications are not a major concern, in that the response for each member of a given composite resembles that of other members of the composite: these figures consider each ENSO event separately, and for nearly all metrics (Eurasian T2m the lone exception) shown on these figures and for both boreal winter and spring, the ensemble-mean response to events with similar SST anomalies in the Niño3.4 region indices is similar.

3. The QBO phase in our experiments is not synchronized with the observed QBO or among the experiments, and hence any nonlinear interactions between the QBO and ENSO that may exist in nature (Calvo et al. 2009; Garfinkel and Hartmann 2010) are averaged out in our results.

For nearly all metrics examined, the response to extreme EN events (e.g. 97/98) is proportionately stronger than that for moderate events in winter but not in spring, in agreement with Richter et al. (2015) and Zhou et al. (2018) in winter and with Rao and Ren (2016b) in spring (though we note that Rao and Ren (2016b) focused on midwinter). Our integrations are more similar to those of Richter et al. (2015) in that we use historical SSTs and not idealized SSTs, and it is conceivable that the specific way in which the SST anomalies in Rao and Ren (2016b) and Zhou et al. (2018) are constructed could lead to some of the discrepancies among the results of the various studies. As integrations with historical SSTs can be more easily compared to observations, they best provide the context with which to interpret nonlinearities inferred from the short observational record. Little can be concluded from the observational record due to the large amount of internal variability - cf. the scatter on Figs. 2 and 4 -and the experiments examined here indicate that no such nonlinearity exists at least in winter.

The midwinter Arctic stratospheric response to CP EN events is weaker than the response to EP EN events (Fig. 5). In fact, the composited Arctic stratospheric response in winter to CP EN events is not statistically significant, and only in spring is a robust response apparent to $\mathrm{CP} \mathrm{EN}$ events. These conclusions are consistent with Garfinkel et al. (2013) who imposed slightly weaker SST anomalies in their CP experiments and found a concomitantly weaker stratospheric response that developed later in the season. These conclusions are also generally similar to those of Hegyi et al. (2014) who find little difference in the stratospheric response if idealized SST anomalies of identical magnitude are placed alternately in the Central or Eastern Pacific. In contrast, the coupled ocean-atmosphere experiments of Calvo et al. (2017) indicate that CP EN has no effect on the vortex even in spring, but that study considered $43 \mathrm{CP}$ EN events, and as shown in Fig. 5c, d a larger composite size is necessary before differences become robust.

The results presented in this work are all based on GEOSCCM and hence must be confirmed with other models and modeling configurations. However the model we consider simulates a realistic amount of variability over most of the key regions we identified (see Appendix B). Overall, our results suggest that it will be difficult to discern robust nonlinearities in the response to ENSO in the observational record until composite sizes grow substantially due to the smallness of the signal-to-noise ratio.

Acknowledgements This study was supported by the Israel Science Foundation (Grant Number 1558/14) and by a European Research Council starting grant under the European Union's Horizon 2020 research and innovation programme (Grant Agreement No. 677756). We thank those involved in model development at GSFC-GMAO, and support by the NASA MAP program. High-performance computing resources were provided by the NASA Center for Climate Simulation (NCCS). We thank Valentina Aquila from American University, Washington DC, USA. for making available some of the GEOSCCM integrations used here, and our anonymous reviewers for their constructive comments. El Niño indices based on the ERSSTv5 data were downloaded from http://www.cpc.ncep.noaa.gov/data/indices/ersst 5.nino.mth.81-10.ascii. 
Open Access This article is distributed under the terms of the Creative Commons Attribution 4.0 International License (http://creativeco mmons.org/licenses/by/4.0/), which permits unrestricted use, distribution, and reproduction in any medium, provided you give appropriate credit to the original author(s) and the source, provide a link to the Creative Commons license, and indicate if changes were made.

\section{Appendix A}

Several different definitions have been used to classify winters as EN or LN, and here we explore sensitivity to the classification method used. We consider three different classification methods:

1. NDJF mean temperatures in the Niño3.4 region (as in main body).

2. The National Oceanic and Atmospheric Administration (NOAA) Climate Prediction Center definition (used by Polvani et al. 2017). Namely, if the 3-month running mean anomalies in SSTs over the Niño3.4 region exceeds either $-0.5 \mathrm{C}$ or $+0.5 \mathrm{C}$ for a minimum of five consecutive overlapping 3-month seasons (DJF, JFM etc.), then an El-Niño or La-Niña event is defined.
3. A new definition that better captures the dynamics behind SSWs that occur during different ENSO phases, and whose main feature is to define an ENSO season separately for SSW years and for non-SSW years. Namely, in a winter with a SSW we evaluate the mean Niño3.4 index in the two months before and the month of the SSW event, while in non SSW years we take the DJF mean. Such a definition can associate a SSW event with ENSO if the early winter Niño3.4 index was anomalous in the months preceding an SSW event, but the Niño3.4 index returned to more normal conditions later in winter. This definition explicitly ignores anomalous sea surface temperature after the SSW event.

In all cases we focus on SSTs in the Niño3.4 region in version 5 of ERSST dataset (Huang et al. 2017) with a 1980-2009 base period. Table 4 lists the years for the 3 different definitions. One can see easily that the years chosen are nearly the same for all three definitions, and hence in the main text we adopt the simplest possible definition.
Table 4 Years composited as EN and LN for three different ENSO definitions. Details are in Appendix A

\begin{tabular}{|c|c|c|c|c|c|c|}
\hline \multicolumn{7}{|c|}{ Years classified as El Niño or La Nina for three definitions } \\
\hline \multirow[t]{2}{*}{ Year } & \multicolumn{3}{|l|}{ EN } & \multicolumn{3}{|l|}{$\mathrm{LN}$} \\
\hline & 5 months & wrt SSW & NDJF & 5 months & wrt SSW & NDJF \\
\hline 1958 & 1958 & 1958 & 1958 & - & - & - \\
\hline 1959 & 1959 & - & - & - & - & - \\
\hline 1960 & - & - & - & - & - & - \\
\hline 1961 & - & - & - & - & - & - \\
\hline 1962 & - & - & - & - & 1962 & 1962 \\
\hline 1963 & - & - & - & - & 1963 & 1963 \\
\hline 1964 & 1964 & 1964 & 1964 & - & - & - \\
\hline 1965 & - & - & - & 1965 & 1965 & 1965 \\
\hline 1966 & 1966 & 1966 & 1966 & - & - & - \\
\hline 1967 & - & - & - & - & 1967 & 1967 \\
\hline 1968 & - & - & - & 1968 & 1968 & 1968 \\
\hline 1969 & 1969 & 1969 & 1969 & - & - & - \\
\hline 1970 & 1970 & - & - & - & - & - \\
\hline 1971 & - & - & - & 1971 & 1971 & 1971 \\
\hline 1972 & - & - & - & 1972 & 1972 & 1972 \\
\hline 1973 & 1973 & 1973 & 1973 & - & - & - \\
\hline 1974 & - & - & - & 1974 & 1974 & 1974 \\
\hline 1975 & - & - & - & 1975 & 1975 & 1975 \\
\hline 1976 & - & - & - & 1976 & 1976 & 1976 \\
\hline 1977 & 1977 & 1977 & 1977 & - & - & - \\
\hline 1978 & 1978 & 1978 & 1978 & - & - & - \\
\hline 1979 & - & - & - & - & - & - \\
\hline 1980 & 1980 & - & - & - & - & - \\
\hline
\end{tabular}


Table 4 (continued)

\begin{tabular}{|c|c|c|c|c|c|c|}
\hline Years & $\mathrm{ied}$ as $\mathrm{El} \mathrm{Ni}$ & a Nina for & efinition & & & \\
\hline Year & EN & & & LN & & \\
\hline & 5 months & wrt SSW & NDJF & 5 months & wrt SSW & NDJF \\
\hline 1981 & - & - & - & - & - & - \\
\hline 1982 & - & - & - & - & - & - \\
\hline 1983 & 1983 & 1983 & 1983 & - & - & - \\
\hline 1984 & - & - & - & - & 1984 & 1984 \\
\hline 1985 & - & - & - & 1985 & 1985 & 1985 \\
\hline 1986 & - & - & - & - & - & - \\
\hline 1987 & 1987 & 1987 & 1987 & - & - & - \\
\hline 1988 & 1988 & 1988 & 1988 & - & - & - \\
\hline 1989 & - & - & - & 1989 & 1989 & 1989 \\
\hline 1990 & - & - & - & - & - & - \\
\hline 1991 & - & - & - & - & - & - \\
\hline 1992 & 1992 & 1992 & 1992 & - & - & - \\
\hline 1993 & - & - & - & - & - & - \\
\hline 1994 & - & - & - & - & - & - \\
\hline 1995 & 1995 & 1995 & 1995 & - & - & - \\
\hline 1996 & - & - & - & 1996 & 1996 & 1996 \\
\hline 1997 & - & - & - & - & - & - \\
\hline 1998 & 1998 & 1998 & 1998 & - & - & - \\
\hline 1999 & - & - & - & 1999 & 1999 & 1999 \\
\hline 2000 & - & - & - & 2000 & 2000 & 2000 \\
\hline 2001 & - & - & - & 2001 & 2001 & 2001 \\
\hline 2002 & - & - & - & - & - & - \\
\hline 2003 & 2003 & 2003 & 2003 & - & - & - \\
\hline 2004 & - & - & - & - & - & - \\
\hline 2005 & 2005 & 2005 & 2005 & - & - & - \\
\hline 2006 & - & - & - & - & 2006 & 2006 \\
\hline 2007 & 2007 & 2007 & 2007 & - & - & - \\
\hline 2008 & - & - & - & 2008 & 2008 & 2008 \\
\hline 2009 & - & - & - & - & 2009 & 2009 \\
\hline 2010 & 2010 & 2010 & 2010 & - & - & - \\
\hline 2011 & - & - & - & 2011 & 2011 & 2011 \\
\hline 2012 & - & - & - & 2012 & 2012 & 2012 \\
\hline 2013 & - & - & - & - & - & - \\
\hline
\end{tabular}

\section{Appendix B: Variance in GEOSCCM}

The main text examined the atmospheric response to different ENSO events, and paid close attention to the emergence of a robust signal from the noise of internal atmospheric variability. Specifically, there is a wide range of responses among the 41 members, and this is reflected in the wide scatter in Figs. 2, 4 and 6 and the size of the error bars in Figs. 3, 5 and 7. The large amount of internal variability in these figures makes it difficult to evaluate whether the model response to ENSO is realistic (Deser et al. 2017). However a necessary prerequisite for comparing observed and modeled ENSO teleconnections is for the model to simulate a similar amount of variance as compared to that observed, as otherwise the model does not satisfactorily capture internal atmospheric variability (Deser et al. 2017). We therefore assess whether GEOSCCM simulates a realistic amount of variance for each metric discussed in the main text in Fig. 12. We evaluate the realism of the variance by computing the variance in each region for each of the 41 ensemble members, sort the variance for the 41 members, and evaluate where the observed/reanalysis variance would lie if we were to consider it as "ensemble member 42 ". The range of model variance is indicated with a vertical line on Fig. 12, and the observed variance is indicated with a diamond. 


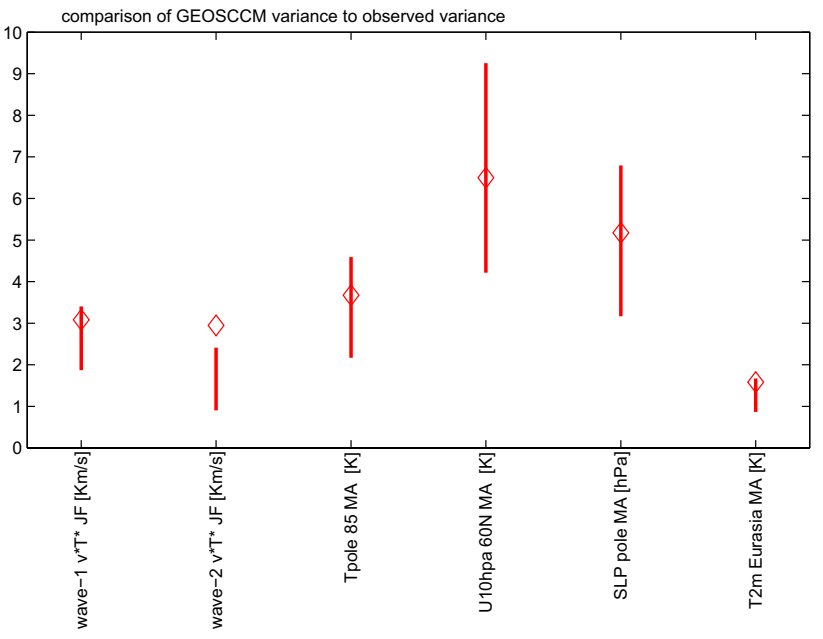

Fig. 12 Comparison of the variance in each member of the GEOSCCM ensemble (vertical line) to the variance in reanalysis data for six key metrics discussed in the text, with the GEOSCCM range corresponding to the max and min of all ensemble members. Wave flux for wave- 1 and 2 are calculated in January and February while the other four metrics are calculated in March and April

For wave-1 heat flux at $100 \mathrm{hPa}$, the variance in reanalysis data lies well within the variance simulated by GEOSCCM, and hence we expect that our conclusions with regards to the effect of ENSO in this region are relevant to nature as well. However, GEOSCCM simulates too-little wave-2 heat flux variance. Hence our conclusions with regard to wave- 2 must be confirmed with other models.

GEOSCCM simulates a realistic amount of variance in the springtime polar stratosphere (though the early-winter vortex has somewhat too-little variability), in sea level pressure over the pole, and in Eurasian surface temperature (Fig. 12). Therefore, we conclude that for most metrics examined in this paper, GEOSCCM simulates a reasonable amount of internal variability.

\section{References}

Andrews DG, Leovy CB, Holton JR (1987) Middle atmosphere dynamics, vol 40. Academic press, Boston

Ashok K, Behera SK, Rao SA, Weng H, Yamagata T (2007) El Niño Modoki and its possible teleconnection. J Geophys Res (Oceans) 112:C11,007. https://doi.org/10.1029/2006JC003798

Baldwin MP, Dunkerton TJ (1999) Propagation of the Arctic Oscillation from the stratosphere to the troposphere. J Geophys Res 104(D24):30,937-30,946

Baldwin MP, Stephenson DB, Thompson DWJ, Dunkerton TJ, Charlton AJ, O'Neill A (2003) Stratospheric memory and skill of extendedrange weather forecasts. Science. https://doi.org/10.1126/scien ce. 1087143

Barnston AG, Livezey RE (1987) Classification, seasonality and persistence of low-frequency atmospheric circulation patterns. Mon Weather Rev 115:1083-1126
Barriopedro D, Calvo N (2014) On the relationship between ENSO, stratospheric sudden warmings, and blocking. J Climate 27(12):4704-4720

Bell CJ, Gray LJ, Charlton-Perez AJ, Joshi MM, Scaife AA (2009) Stratospheric communication of El Niño teleconnections to European winter. J Climate 22:4083-4096. https://doi. org/10.1175/2009JCLI2717.1

Brönnimann S (2007) The impact of El Nino/Southern oscillation on European climate. Rev Geophys 45:3003

Butler AH, Polvani LM (2011) El Nino, La Nina, and stratospheric sudden warmings: a reevaluation in light of the observational record. Geophys Res Lett 38:L13,807. https://doi.org/10.1029/2011G L048084

Butler AH, Polvani LM, Deser C (2014) Separating the stratospheric and tropospheric pathways of El Niño-southern oscillation teleconnections. Environ Res Lett 9(2):024,014

Cagnazzo C, Manzini E, Calvo N, Douglass A, Akiyoshi H, Bekki S, Chipperfield M, Dameris M, Deushi M, Fischer A, Garny H, Gettelman A, Giorgetta MA, Plummer D, Rozanov E, Shepherd TG, Shibata K, Stenke A, Struthers H, Tian W (2009) Northern winter stratospheric temperature and ozone responses to ENSO inferred from an ensemble of chemistry climate models. Atmos Chem Phys 9:8935-8948

Calvo N, Giorgetta MA, Garcia-Herrera R, Manzini E (2009) Nonlinearity of the combined warm enso and qbo effects on the northern hemisphere polar vortex in maecham5 simulations. J Geophys Res. https://doi.org/10.1029/2008JD011445

Calvo N, Iza M, Hurwitz MM, Manzini E, Pena-Ortiz C, Butler A, Cagnazzo C, Ineson S, Garfinkel C (2017) Northern Hemisphere stratospheric pathway of different El Niño flavors in CMIP5 models. J Climate 30:4351-4371. https://doi.org/10.1175/ JCLI-D-16-0132.1

Camp CD, Tung KK (2007) Stratospheric polar warming by ENSO in winter, a statistical study. Geophys Res Lett 34:L04809. https:// doi.org/10.1029/2006GL028521

Capotondi A, Wittenberg AT, Newman M, Di Lorenzo E, Yu JY, Braconnot P, Cole J, Dewitte B, Giese B, Guilyardi E, Jin FF, Karnauskas K, Kirtman B, Lee T, Schneider N, Xue Y, Yeh SW (2015) Understanding ENSO diversity. Bull Am Meteorol Soc 96(6):921-938. https://doi.org/10.1175/BAMS-D-13-00117.1

Charlton AJ, Polvani LM (2007) A new look at stratospheric sudden warmings. Part I: climatology and modeling benchmarks. J Climate 20:449-469. https://doi.org/10.1175/JCLI3996.1

Charlton AJ, O’Neill A, Stephenson D, Lahoz W, Baldwin M (2003) Can knowledge of the state of the stratosphere be used to improve statistical forecasts of the troposphere? Q J R Meteorol Soc 129(595):3205-3224. https://doi.org/10.1256/qj.02.232

Chatterjee S, Hadi AS (2012) Regression analysis by example, 5th edn. Wiley, New York

Dee D, Uppala S, Simmons A, Berrisford P, Poli P, Kobayashi S, Andrae U, Balmaseda M, Balsamo G, Bauer P et al (2011) The era-interim reanalysis: configuration and performance of the data assimilation system. Q J R Meteorol Soc 137(656):553-597

Deser C, Simpson IR, McKinnon KA, Phillips AS (2017) The northern hemisphere extratropical atmospheric circulation response to enso: how well do we know it and how do we evaluate models accordingly? J Climate 30(13):5059-5082

Ding S, Chen W, Graf HF, Guo Y, Nath D (2017) Distinct winter patterns of tropical pacific convection anomaly and the associated extratropical wave trains in the northern hemisphere. Climate Dyn. https://doi.org/10.1007/s00382-017-3995-0

Domeisen DIV, Butler AH, Fröhlich K, Bittner M, Müller W, Baehr J (2015) Seasonal predictability over Europe arising from El Niño and stratospheric variability in the MPI-ESM seasonal prediction system. J Climate 28(1):256-271 
Domeisen DI, Garfinkel C, Butler AH (2019) The teleconnection of El Niño southern oscillation to the stratosphere. Rev Geophys 57:5-47. https://doi.org/10.1029/2018RG000596

Frauen C, Dommenget D, Tyrrell N, Rezny M, Wales S (2014) Analysis of the nonlinearity of El Niño-southern oscillation teleconnections. J Climate 27(16):6225-6244

Free M, Seidel DJ (2009) Observed El Niño-Southern oscillation temperature signal in the stratosphere. J Geophys Res 114:D23108. https://doi.org/10.1029/2009JD012420

Garcia-Herrera R, Calvo N, Garcia RR, Giorgetta MA (2006) Propagation of ENSO temperature signals into the middle atmosphere: a comparison of two general circulation models and ERA-40 reanalysis data. J Geophys Res. https://doi.org/10.1029/2005JD006061

Garfinkel CI, Hartmann DL (2007) Effects of the El-Nino Southern oscillation and the Quasi-Biennial oscillation on polar temperatures in the stratosphere. J Geophys Res Atmos 112:D19112. https ://doi.org/10.1029/2007JD008481

Garfinkel CI, Hartmann DL (2008) Different ENSO teleconnections and their effects on the stratospheric polar vortex. J Geophys Res Atmos. https://doi.org/10.1029/2008JD009920

Garfinkel CI, Hartmann DL (2010) The influence of the quasi-biennial oscillation on the north pacific and El-niño teleconnections. J Geophys Res 115:D20116. https://doi.org/10.1029/2010JD014181

Garfinkel CI, Hartmann DL, Sassi F (2010) Tropospheric precursors of anomalous northern hemisphere stratospheric polar vortices. J Climate. https://doi.org/10.1175/2010JCLI3010.1

Garfinkel CI, Butler AH, Waugh DW, Hurwitz MM (2012) Why might SSWs occur with similar frequency in El Niño and La Niña winters? J Geophys Res 117:D19,106. https://doi.org/10.1029/2012J D017777

Garfinkel CI, Hurwitz MM, Waugh DW, Butler AH (2013) Are the teleconnections of central Pacific and eastern Pacific El Niño distinct in boreal wintertime? Climate Dyn. https://doi.org/10.1007/ s00382-012-1570-2

Garfinkel CI, Son SW, Song K, Aquila V, Oman LD (2017) Stratospheric variability contributed to and sustained the recent hiatus in Eurasian winter warming. Geophys Res Lett 44(1):374-382. https://doi.org/10.1002/2016GL072035

Garfinkel CI, Gordon A, Oman LD, Li F, Davis S, Pawson S (2018a) Nonlinear response of tropical lower stratospheric temperature and water vapor to ENSO. Atmos Chem Phys 18(7):4597-4615. https://doi.org/10.5194/acp-2017-520

Garfinkel CI, Weinberger I, White I, Oman L, Aquila V, Lim YK (2018b) The salience of nonlinearities in the boreal winter response to ENSO: North Pacific and North America. Climate Dyn. https://doi.org/10.1007/s00382-018-4386-x

Graf H, Zanchettin D (2012) Central Pacific El Nino, the "subtropical bridge", and Eurasian climate. J Geophys Res. https://doi. org/10.1029/2011JD016493

Halpert MS, Ropelewski CF (1992) Surface temperature patterns associated with the Southern Oscillation. J Climate 5:577-593. https://doi.org/10.1175/1520-0442(1992)005<3C0577:STPAW $\mathrm{T}>2.0 . \mathrm{CO} ; 2$

Hamilton K (1993) An examination of observed Southern Oscillation effects in the northern hemisphere stratosphere. J Atmos Sci 50:3468-3473

Hegyi BM, Deng Y, Black RX, Zhou R (2014) Initial transient response of the winter polar stratospheric vortex to idealized equatorial Pacific sea surface temperature anomalies in the NCAR WACCM. J Climate 27(7):2699-2713

Horel JD, Wallace JM (1981) Planetary scale atmospheric phenomena associated with the Southern Oscillation. Mon Weather Rev 109:813-829

Huang B, Thorne PW, Banzon VF, Boyer T, Chepurin G, Lawrimore JH, Menne MJ, Smith TM, Vose RS, Zhang HM (2017) Extended reconstructed sea surface temperature, version 5
(ERSSTv5): upgrades, validations, and intercomparisons. J Climate 30(20):8179-8205

Hurwitz MM, Calvo N, Garfinkel CI, Butler AH, Ineson S, Cagnazzo C, Manzini E, Peña-Ortiz C (2014) Extra-tropical atmospheric response to enso in the CMIP5 models. Climate Dyn 43(12):3367-3376

Ineson S, Scaife AA (2009) The role of the stratosphere in the European climate response to El Nino. Nat Geosci 2:32-36. https:// doi.org/10.1038/ngeo381

Iza M, Calvo N (2015) Role of stratospheric sudden warmings on the response to central Pacific El Niño. Geophys Res Lett 42(7):24822489. https://doi.org/10.1002/2014GL062935

Iza M, Calvo N, Manzini E (2016) The stratospheric pathway of La Niña. J Climate 29(24):8899-8914

Jiménez-Esteve B, Domeisen DIV (2018) The tropospheric pathway of the ENSO-north Atlantic teleconnection. J Climate 31(11):45634584. https://doi.org/10.1175/JCLI-D-17-0716.1

Johnson NC, Kosaka Y (2016) The impact of eastern equatorial Pacific convection on the diversity of boreal winter El Niño teleconnection patterns. Climate Dyn 47(12):3737-3765

Kidston J, Scaife AA, Hardiman SC, Mitchell DM, Butchart N, Baldwin MP, Gray LJ (2015) Stratospheric influence on tropospheric jet streams, storm tracks and surface weather. Nature Geosci 8(6):433-440

Kretschmer M, Coumou D, Agel L, Barlow M, Tziperman E, Cohen J (2018) More-persistent weak stratospheric polar vortex states linked to cold extremes. Bull Am Meteorol Soc 99(1):49-60. https ://doi.org/10.1175/BAMS-D-16-0259.1

Larkin NK, Harrison DE (2005) Global seasonal temperature and precipitation anomalies during El Niño autumn and winter. Geophys Res Lett 32:L16705. https://doi.org/10.1029/2005GL022860

L'Heureux ML, Tippett MK, Kumar A, Butler AH, Ciasto LM, Ding Q, Harnos K, Johnson NC (2017) Strong relations between ENSO and the Arctic Oscillation in the North American multimodel ensemble. Geophys Res Lett. https://doi.org/10.1002/2017G L074854

Li Y, Lau NC (2013) Influences of ENSO on stratospheric variability, and the descent of stratospheric perturbations into the lower troposphere. J Climate 26(13):4725-4748. https://doi.org/10.1175/ JCLI-D-12-00581.1

Manzini E, Giorgetta MA, Kornbluth L, Roeckner E (2006) The influence of sea surface temperatures on the northern winter stratosphere: ensemble simulations with the MAECHAM5 model. J Climate 19:3863-3881

McDonald JH (2014) Handbook of biological statistics, vol 3. Sparky House Publishing, Baltimore

Molod A, Takacs L, Suarez M, Bacmeister J, Song IS, Eichmann A (2012) The GEOS-5 atmospheric general circulation model: mean climate and development from MERRA to Fortuna. Technical Report series on global modeling and data assimilation 28. https ://gmao.gsfc.nasa.gov/pubs/docs/Molod484.pdf

Oman LD, Douglass AR (2014) Improvements in total column ozone in GEOSCCM and comparisons with a new ozone-depleting substances scenario. J Geophys Res Atmos. https://doi. org/10.1002/2014JD021590

Pawson S, Stolarski RS, Douglass AR, Newman PA, Nielsen JE, Frith SM, Gupta ML (2008) Goddard Earth Observing System chemistry-climate model simulations of stratospheric ozone-temperature coupling between 1950 and 2005. J Geophys Res Atmos 113:D12103. https://doi.org/10.1029/2007JD009511

Polvani LM, Waugh DW (2004) Upward wave activity flux as a precursor to extreme stratospheric events and subsequent anomalous surface weather regimes. J Climate 17:3548-3554

Polvani LM, Sun L, Butler AH, Richter JH, Deser C (2017) Distinguishing stratospheric sudden warmings from ENSO as key 
drivers of wintertime climate variability over the North Atlantic and Eurasia. J Climate 30(6):1959-1969

Rao J, Ren R (2016a) Asymmetry and nonlinearity of the influence of ENSO on the northern winter stratosphere: 1. Observations. J Geophys Res Atmos 121(15):9000-9016. https://doi. org/10.1002/2015JD024520

Rao J, Ren R (2016b) Asymmetry and nonlinearity of the influence of ENSO on the northern winter stratosphere: 2 . Model study with WACCM. J Geophys Res Atmos 121(15):9017-9032. https://doi. org/10.1002/2015JD024520

Richter JH, Deser C, Sun L (2015) Effects of stratospheric variability on El Niño teleconnections. Environ Res Lett 10(12):124,021

Rienecker et al MM (2008) The GEOS-5 data assimilation systemdocumentation of versions 5.0.1, 5.1.0, and 5.2.0. Technical Report Series on Global Modeling and Data Assimilation 27. http://gmao.gsfc.nasa.gov/pubs/docs/Rienecker369.pdf

Rienecker MM, Suarez MJ, Gelaro R, Todling R, Bacmeister J, Liu E, Bosilovich MG, Schubert SD, Takacs L, Kim GK, Bloom S, Chen J, Collins D, Conaty A, da Silva A, Gu W, Joiner J, Koster RD, Lucchesi R, Molod A, Owens T, Pawson S, Pegion P, Redder CR, Reichle R, Robertson FR, Ruddick AG, Sienkiewicz M, Woollen J (2011) MERRA: NASA's modern-era retrospective analysis for research and applications. J Climate 24:3624-3648. https://doi. org/10.1175/JCLI-D-11-00015.1

Rodríguez-Fonseca B, Suárez-Moreno R, Ayarzagüena B, López-Parages J, Gómara I, Villamayor J, Mohino E, Losada T, CastañoTierno A (2016) A review of ENSO influence on the North Atlantic. A non-stationary signal. Atmosphere 7(7):87

Ropelewski CF, Halpert MS (1987) Global and regional scale precipitation patterns associated with the El Niño/Southern Oscillation. Mon Weather Rev 115:1606. https://doi.org/10.1175/15200493(1987)115<1606:GARSPP > 2.0.CO;2

Sassi F, Kinnison D, Bolville BA, Garcia RR, Roble R (2004) Effect of El-Niño Southern Oscillation on the dynamical, thermal, and chemical structure of the middle atmosphere. J Geophys Res. https ://doi.org/10.1029/2003JD004434

Seviour WJ, Mitchell DM, Gray LJ (2013) A practical method to identify displaced and split stratospheric polar vortex events. Geophys Res Lett 40(19):5268-5273

Sigmond M, Scinocca J, Kharin V, Shepherd T (2013) Enhanced seasonal forecast skill following stratospheric sudden warmings. Nat Geosci 6(2):98-102. https://doi.org/10.1038/ngeo1698

Sjoberg JP, Birner T (2012) Transient tropospheric forcing of sudden stratospheric warmings. J Atmos Sci. https://doi.org/10.1175/ JAS-D-11-0195.1

Smith KL, Kushner PJ (2012) Linear interference and the initiation of extratropical stratosphere-troposphere interactions. J Geophys Res Atmos 117:D13107. https://doi.org/10.1029/2012JD017587

Smith KL, Fletcher CG, Kushner PJ (2010) The role of linear interference in the annular mode response to extratropical surface forcing. J Climate 23:6036-6050. https://doi.org/10.1175/2010JCLI3606.1

Song K, Son SW (2018) Revisiting the ENSO-SSW relationship. J Climate 31(6):2133-2143
Sung MK, Kim BM, An SI (2014) Altered atmospheric responses to Eastern Pacific and Central Pacific El Niños over the North Atlantic region due to stratospheric interference. Climate Dyn 42(1-2):159-170

Taguchi M, Hartmann DL (2006) Increased occurrence of stratospheric sudden warming during El Niño as simulated by WAACM. J Climate 19:324-332. https://doi.org/10.1175/JCLI3655.1

Thompson DWJ, Baldwin MP, Wallace JM (2002) Stratospheric connection to northern hemisphere wintertime weather: implications for prediction. J Climate 15:1421-1428. https://doi. org/10.1175/1520-0442(2002)015

Toniazzo T, Scaife AA (2006) The influence of ENSO on winter North Atlantic climate. Geophys Res Lett. https://doi.org/10.1029/2006G L027881

Trenberth KE, Branstator GW, Karoly D, Kumar A, Lau NC, Ropelewski C (1998) Progress during TOGA in understanding and modeling global teleconnections associated with tropical sea surface temperatures. J Geophys Res 103:14291-14324

van Loon H, Labitzke K (1987) The Southern Oscillation. part V: the anomalies in the lower stratosphere of the northern hemisphere in winter and a comparison with the Quasi-Biennial Oscillation. Mon Weather Rev 115:357-369

White I, Garfinkel CI, Gerber EP, Jucker M, Aquila V, Oman LD (2019) The downward influence of sudden stratospheric warmings: association with tropospheric precursors. J Climate 32(1):85-108

Wilks DS (2016) "The stippling shows statistically significant grid points": how research results are routinely overstated and overinterpreted, and what to do about it. Bull Am Meteorol Soc 97(12):2263-2273. https://doi.org/10.1175/BAMS-D-15-00267.1

Xie F, Li JP, Tian WS, Feng J (2012) Signals of El Niño modoki in the tropical tropopause layer and stratosphere. Atmos Chem Phys. https://doi.org/10.5194/acp-12-5259-2012

Yu JY, Kim ST (2011) Relationships between extratropical sea level pressure variations and the Central Pacific and Eastern Pacific types of ENSO. J Climate 24(3):708-720

Yu JY, Zou Y, Kim ST, Lee T (2012) The changing impact of El Niño on us winter temperatures. Geophys Res Lett. https://doi. org/10.1029/2012GL052483

Zhou X, Li J, Xie F, Chen Q, Ding R, Zhang W, Li Y (2018) Does extreme El Niño have a different effect on the stratosphere in boreal winter than its moderate counterpart? J Geophys Res Atmos 123(6):3071-3086

Publisher's Note Springer Nature remains neutral with regard to jurisdictional claims in published maps and institutional affiliations. 